\title{
Study of Crystallization and Composition on Silicon Oxycarbide (SiOC) and Silicon Boron Oxycarbide (SiBOC) Ceramics Obtained from Alkoxysilanes Precursors
}

\author{
Mariana G. Segatelli, ${ }^{\circledR a}$ Patricia M. Sanchez, ${ }^{a}$ Livia R. C. Silva, ${ }^{a}$ Maria A. Silva, ${ }^{a}$ \\ César R. T. Tarley, ${ }^{\circledR *}{ }^{*}$ Paulo R. C. da Silva ${ }^{b}$ and Emerson S. Ribeiro ${ }^{\circledR c}$ \\ ${ }^{a}$ Departamento de Química, Universidade Estadual de Londrina (UEL), \\ Rodovia Celso Garcia Cid, PR 445, km 380, 86057-970 Londrina-PR, Brazil \\ ${ }^{b}$ Departamento de Física, Universidade Estadual de Londrina (UEL), \\ Rodovia Celso Garcia Cid, PR 445, km 380, 86057-970 Londrina-PR, Brazil \\ 'Instituto de Química, Universidade Federal do Rio de Janeiro (UFRJ), \\ Avenida Athos da Silveira Ramos, 149, 21941-909 Rio de Janeiro-RJ, Brazil
}

\begin{abstract}
This work deals on the preparation of silicon oxycarbide ( $\mathrm{SiOC}$ ) and silicon boron oxycarbide (SiBOC) ceramics from pyrolysis involving alkoxysilanes with different organic groups. Boron content, organic substituent and annealing time were evaluated on crystallization and composition of resulting ceramics. B-free precursors composed of methyltriethoxysilane (MTES), phenyltriethoxysilane (PTES) and vinyltrimethoxysilane (VTMS) were obtained by the sol-gel method, whilst B-containing precursors were prepared by adding to each alkoxysilane a proper amount of boric acid resulting in $\mathrm{B} / \mathrm{Si}$ atomic ratios of 0.1 and 0.5 . Precursors were pyrolyzed at $1500{ }^{\circ} \mathrm{C}$ for 1 and $3 \mathrm{~h}$ to produce respective SiOC and SiBOC ceramics. X-ray diffraction (XRD) patterns revealed enhanced $\mathrm{SiC}$ phase crystallization for PTES-derived ceramics, followed by those containing vinyl and methyl groups, which was also confirmed by X-ray photoelectron spectroscopy (XPS) from percentages of $\mathrm{Si}-\mathrm{C}$ and $\mathrm{Si}-\mathrm{O}$ bonds. $\mathrm{Csp}^{2}$ and $\mathrm{Csp}^{3}$ amounts varied among ceramics, indicating direct influence of organic substituent on conductive carbon phase development. Boron addition induced the growth of $\mathrm{SiC}$ crystallites, having more evident effect in matrices with higher proportions of amorphous fraction and lower residual carbon amounts. Organic group nature, boron content and annealing time played an important role for production and evolution of $\mathrm{SiC}$ and $\mathrm{C}$ phases into ceramics.
\end{abstract}

Keywords: polymer-derived ceramics, boron, sol-gel method, annealing, free carbon phase

\section{Introduction}

Silicon oxycarbide (SiOC) based materials have attracted great attention in Si-polymer derived ceramics (PDCs) field due to their excellent mechanical, thermal, electrical, optical, oxidation resistance and low densities properties. ${ }^{1,2}$ These characteristics make them suitable in a wide application range including high resistance SiOC fibers and ceramic matrix composites, ${ }^{3,4}$ high-temperature receivers and ceramics for thermal insulation, ${ }^{5,6} \mathrm{Li}$-ion batteries and voltammetric sensors, ${ }^{7,8}$ platforms for integrated photonics and luminescent thin films, ${ }^{9,10}$ ceramic coatings for anti-oxidation performance as well as protective layers for high-temperature corrosion, ${ }^{11,12}$

*e-mail: tarley@uel.br ceramic membranes for water purification and ceramic foams, ${ }^{13,14}$ among others.

SiOC materials are usually prepared by controlled pyrolysis of poly(organosiloxanes) precursors, under inert atmosphere. ${ }^{15-18}$ Their micro/nanostructures widely change according to molecular architecture and composition of selected precursors together with pyrolysis conditions such as temperature, isothermal annealing, atmosphere, and heating/cooling rates. ${ }^{17,19}$

In general, when poly(organosiloxanes) are thermally heated from 800 to $1000{ }^{\circ} \mathrm{C}$, a mixed amorphous ceramic network composed mainly by random arrangements of $\mathrm{Si}$ sites tetracoordinate with $\mathrm{O}$ and $\mathrm{C}$ atoms, commonly described as $\mathrm{SiO}_{\mathrm{x}} \mathrm{C}_{4-\mathrm{x}}, 0 \leq \mathrm{x} \leq 4$, is obtained. Furthermore, polyaromatic carbon species are continuously produced into ceramic matrix due to incomplete thermal degradation 
of organic groups attached to polymeric chain. This gives rise a second phase in SiOC matrices, named as free carbon $\left(\mathrm{C}_{\text {free }}\right)$, which is constituted by a carbon atoms network in $\mathrm{sp}^{3}$ and $\mathrm{sp}^{2}$ hybridizations..$^{20,21}$ At temperatures higher to $1000{ }^{\circ} \mathrm{C}$, homogeneous amorphous matrix undergoes structural transformations promoted by the redistribution reactions among the different $\mathrm{Si}$ sites, until a phase separation process is achieved. Around $1300{ }^{\circ} \mathrm{C}$, SiOC begins to decompose, resulting in $\mathrm{SiC}, \mathrm{SiO}_{2}$ and $\mathrm{C}$ phases (equation 1). ${ }^{22}$ As the temperature arises, carbothermal reduction reaction is favored, basically yielding $\mathrm{SiC}$ from reaction between free carbon and $\mathrm{SiO}_{2}$ or $\mathrm{Si}-\mathrm{O}$-rich sites, as represented by partials (equations 2 and 3 ) and global (equation 4 ) equations. ${ }^{15}$ Indeed, at high temperatures, two interpenetrating nanosized networks composed of $\mathrm{SiO}_{2}$-rich and $\mathrm{C}$-rich regions, in which the latter comprises $\mathrm{SiC}$ nanocrystals and graphitic carbon structures, are usually obtained, whose proportions are dependent on the precursor chemistry. ${ }^{23}$ According to Kleebe et al. ${ }^{24}$ at high temperatures such as $1450{ }^{\circ} \mathrm{C}$, the phase separation process involves $\mathrm{SiO}_{4}$ and $\mathrm{SiC}_{4}$ rich regions encapsulated by carbon, which initially are composed of finely dispersed graphene layers, and after grow form thicker multi-layer carbon. Such structural arrangement, mainly regarding the existence of free carbon network, justified the thermal stability on mechanical property of SiOC materials.

$$
\begin{aligned}
& 2 \mathrm{SiCO}_{(\mathrm{s})} \rightarrow \mathrm{SiC}_{(\mathrm{s})}+\mathrm{SiO}_{2(\mathrm{~s})}+\mathrm{C}_{(\mathrm{s})} \\
& \mathrm{SiO}_{2(\mathrm{~s})}+\mathrm{C}_{(\mathrm{s})} \rightarrow \mathrm{SiO}_{(\mathrm{g})}+\mathrm{CO}_{(\mathrm{g})} \\
& \mathrm{SiO}_{(\mathrm{g})}+2 \mathrm{C}_{(\mathrm{s})} \rightarrow \mathrm{SiC}_{(\mathrm{s})}+\mathrm{CO}_{(\mathrm{g})} \\
& \mathrm{SiO}_{2(\mathrm{~s})}+3 \mathrm{C}_{(\mathrm{s})} \rightarrow \mathrm{SiC}_{(\mathrm{s})}+2 \mathrm{CO}_{(\mathrm{g})}
\end{aligned}
$$

The incorporation of heteroatoms such as boron into poly(organosiloxanes) can be successfully performed because their molecular structures can be easily tailored. This approach consists in a strategy for producing multicomponent ceramics, besides promotes structural and compositional changes, resulting in characteristics and improved properties of final materials. Specifically, in the SiOC system, B addition leads to the production of silicon boron oxycarbide (SiBOC), which reveals improved high temperature stability, creep resistance and thermooxidative stability when compared to SiOC. ${ }^{25,26}$

$\mathrm{SiBOC}$ materials can be produced cheaply from easily accessible starting reagents. These include alkoxysilanes that assume the general formula $\mathrm{R}_{\mathrm{x}} \mathrm{SiZ}_{4-\mathrm{x}}(\mathrm{x}=1,2,3$, where $\mathrm{R}^{\prime}$ is an organic group and $\mathrm{Z}=$ methoxy, ethoxy groups, among others) and boric acid, $\mathrm{B}(\mathrm{OH})_{3} \cdot \mathrm{SiO}_{2} / \mathrm{B}_{2} \mathrm{O}_{3}$ powders, borane dimethylsulfide and triethylborate have already been employed as boron sources, ${ }^{27-29}$ meanwhile $\mathrm{B}(\mathrm{OH})_{3}$ is the cheapest source, easily available, nontoxic resource and usually chosen to produce boron-containing ceramics. ${ }^{30-32}$

Alkoxysilanes and boric acid readily react through hydrolysis and polycondensation reactions involving the sol-gel chemistry, in the absence of solvent. As a result, B is homogeneously incorporated into siloxane network as trigonal $\mathrm{BO}_{3}$ units via $\mathrm{Si}-\mathrm{O}-\mathrm{B}$ borosiloxane bonds, leading to the formation of amorphous SiBOC ceramics with a mixed network composed of silicon oxycarbide $\left(\mathrm{SiO}_{\mathrm{x}} \mathrm{C}_{4-\mathrm{x}}\right.$, $0 \leq \mathrm{x} \leq 3)$ and boron oxycarbide $\left(\mathrm{BO}_{\mathrm{y}} \mathrm{C}_{3-\mathrm{y}}, 0 \leq \mathrm{y} \leq 2\right)$ units at around $1000{ }^{\circ} \mathrm{C}$. The excellent high-temperature properties described for $\mathrm{SiBOC}$ are attributed to their highly crosslinking structures according to formed $\mathrm{Si}-\mathrm{O}-\mathrm{B}$ bonds..$^{20,30,33}$

It is reported that boron incorporation into $\mathrm{SiOC}$ matrices contributes to the consumption of silicon oxycarbide units, favoring the ceramic matrix crystallization by means of semiconducting $\beta$-SiC phase development, besides inhibits the amorphous $\mathrm{SiO}_{2}$ phase formation. ${ }^{32,34}$ Besides enhanced $\mathrm{SiC}$ production, B incorporation revealed significant effect on free carbon graphitization, resulting in SiBOC ceramics with highly graphitized $\mathrm{C}_{\text {free }}$ and high ceramic yields. ${ }^{30,35}$

As mentioned before, precursor chemistry has influence over resulting ceramics structure and composition. Specifically, both amounts and distributions of $\mathrm{C}_{\text {free }}$ phase produced into ceramic matrix during pyrolysis depend on the organic group bonded to Si-polymer precursor. Organic substituents containing unsaturation, such as phenyl and vinyl groups usually give rise to PDCs with higher $\mathrm{C}_{\text {free }}$ amounts when compared to saturate groups (e.g., methyl and ethyl). ${ }^{36,37}$ As carbothermal reduction reaction (equation 4) reveals a certain dependence with the $C_{\text {free }}$ availability, it is expected that higher carbonaceous phase contents contribute to more effective $\mathrm{SiC}$ crystallization into ceramic matrices. Therefore, the combined use of boron in alkoxysilanes-based precursors containing different organic substituents shows an important role to manufacture multicomponent PDCs, mainly focusing on the improvement of their electric features due to crystalline phases potentially produced in situ. Although some works have already reported the boron addition into alkoxysilanes to produce hybrid $\mathrm{RSiO}_{1.5} / \mathrm{B}_{2} \mathrm{O}_{3}$ gels $(\mathrm{R}=$ methyl $(\mathrm{Me})$, ethyl (Et), vinyl (Vi)), ${ }^{28,38} \mathrm{SiBOC}$ glasses and ceramic fibers, ${ }^{35,39,40}$ ceramic matrix composites (CMCs) involving SiBOC and carbon fibers $(\mathrm{C} / \mathrm{SiBOC})^{41}$ as well as to evaluate the structural evolution ${ }^{30,34,42}$ and mechanical properties ${ }^{25}$ of ceramics employing different temperatures, few efforts have been made concerning a comparative study about its simultaneous use into different modified silicon alkoxides and isothermal annealing over ceramics crystallization at high temperatures. 
This work reports the synthesis of $\mathrm{SiBOC}$ ceramics at $1500{ }^{\circ} \mathrm{C}$ from three polymer precursors, prepared by the sol-gel method, involving methyltriethoxysilane (MTES), phenyltriethoxysilane (PTES) and vinyltrimethoxysilane (VTMS) with different $\mathrm{B} / \mathrm{Si}$ atomic ratios. Corresponding B-free ceramics (SiOC) were also obtained for comparison. The influence of boron content, organic substituent and isothermal annealing on phase crystallization and composition of resulting ceramics was described.

\section{Experimental}

\section{Starting reagents}

Methyltriethoxysilane (MTES), phenyltriethoxysilane (PTES), vinyltrimethoxysilane (VTMS) (Sigma-Aldrich Ltda, São Paulo, Brazil) and boric acid $\left(\mathrm{H}_{3} \mathrm{BO}_{3}\right)$ as boron source (Vetec, Duque de Caxias, Brazil) were used to prepare all preceramic precursors. Hydrochloric acid $(\mathrm{HCl})$ (Vetec, Duque de Caxias, Brazil) and ammonium hydroxide $\left(\mathrm{NH}_{4} \mathrm{OH}\right)$ (Sigma-Aldrich Ltda, São Paulo, Brazil) were employed during hydrolysis and condensation reactions. All the reagents were used as received without any further purification.

\section{Synthesis of SiOC and SiBOC preceramic precursors}

B-free and B-containing samples were prepared by the sol-gel method using MTES, PTES, VTMS and boric acid, according to procedure previously described in literature. ${ }^{34}$

SiBOC precursors were synthesized by adding to each modified alkoxysilane, MTES, PTES and VTMS, a proper amount of boric acid $\left(\mathrm{H}_{3} \mathrm{BO}_{3}\right)$, followed by stirring until their complete dissolution. Compositions containing $\mathrm{B} / \mathrm{Si}$ atomic ratios of 0.1 and 0.5 were prepared. After dissolution, the obtained clean solutions were cast into Teflon molds, followed by gelation step. The wet $\mathrm{B}$-containing precursors were dried for at least 10 days at $70{ }^{\circ} \mathrm{C}$. For comparison, $\mathrm{B}$-free samples, corresponding to $\mathrm{SiOC}$ precursors, were prepared by hydrolysis and condensation reactions, in which each alkoxysilane was hydrolyzed using a $\mathrm{H}_{2} \mathrm{O}$ :silane molar ratio of $1: 1$, at $70{ }^{\circ} \mathrm{C}$ for $15 \mathrm{~min}$, under $1.0 \mathrm{~mol} \mathrm{~L}^{-1}$ $\mathrm{HCl}$ solution. Afterward, the acid solutions were neutralized by addition of a stoichiometric amount of $\mathrm{NH}_{4} \mathrm{OH}$ solution $(30 \%)$. The sols were then gelled and dried for at least 10 days at $70{ }^{\circ} \mathrm{C} .{ }^{34}$

After obtainment, all B-free and B-containing precursors were grinded and sieved in $\leq 106 \mu \mathrm{m}$ sizes (Bertel Industry Metallurgica Ltda, Caieiras, Brazil) to get better control of the particles sizes before characterization. Table 1 illustrates the codes assigned to all preceramic polymers prepared.
Table 1. Codes corresponding to preceramic polymers prepared by the sol-gel method using MTES, PTES, VTMS and boric acid, in B/Si atomic ratios of $0,0.1$ and 0.5

\begin{tabular}{lcc}
\hline Alkoxysilane & B/Si atomic ratio & Preceramic polymer \\
\hline \multirow{3}{*}{ MTES } & 0 & MTES $_{0}$ \\
& 0.1 & MTES $_{0.1}$ \\
\hline \multirow{3}{*}{ PTES } & 0.5 & MTES $_{0.5}$ \\
& 0 & PTES $_{0}$ \\
& 0.1 & PTES $_{0.1}$ \\
\multirow{2}{*}{ VTMS } & 0.5 & PTES $_{0.5}$ \\
& 0 & VTMS $_{0}$ \\
& 0.1 & VTMS $_{0.1}$ \\
\hline
\end{tabular}

MTES: methyltriethoxysilane; PTES: phenyltriethoxysilane; VTMS: vinyltrimethoxysilane.

\section{Obtainment of SiOC and SiBOC ceramics}

$\mathrm{SiOC}$ and $\mathrm{SiBOC}$ ceramic materials were obtained by controlled pyrolysis of each polymer precursor employing a high temperature furnace containing an adapted alumina tube (EDG10P-S, São Carlos, Brazil). Pyrolysis procedure was carried out under argon atmosphere, from room temperature up to $1500{ }^{\circ} \mathrm{C}$, with a heating/cooling rate of $5^{\circ} \mathrm{C} \mathrm{min}^{-1}$ and annealed for 1 and $3 \mathrm{~h}$ at final temperature. Therefore, eighteen ceramic materials based on SiOC and $\mathrm{SiBOC}$ systems containing different $\mathrm{B} / \mathrm{Si}$ atomic ratios, types of alkoxysilanes and annealing times were obtained, as illustrated in Table 2 . The choice of pyrolysis temperature at $1500{ }^{\circ} \mathrm{C}$ is related to development of crystalline phases, mainly composed of graphitic carbon structures and nanosized $\mathrm{SiC}$ crystallites, via carbothermal reduction reaction. ${ }^{43,44}$ Annealing conditions usually contribute to more effective crystallization into ceramic matrices. ${ }^{42,45}$ Therefore, the association between pyrolysis at $1500{ }^{\circ} \mathrm{C}$

Table 2. Codes illustrating general representations for $\mathrm{SiOC}$ and $\mathrm{SiBOC}$ ceramics obtained from the same alkoxysilane and for each set of ceramics with different $\mathrm{B} / \mathrm{Si}$ atomic ratios and annealing times

\begin{tabular}{|c|c|c|c|}
\hline \multirow{2}{*}{$\begin{array}{l}\text { Preceramic } \\
\text { polymer }\end{array}$} & \multirow{2}{*}{$\begin{array}{c}\text { General codes } \\
\text { for } \mathrm{SiOC} \text { and } \\
\text { SiBOC ceramics }\end{array}$} & \multicolumn{2}{|c|}{ Code for ceramics after annealing } \\
\hline & & $1 \mathrm{~h}$ & $3 \mathrm{~h}$ \\
\hline $\mathrm{MTES}_{0}$ & & $\mathrm{CMS}_{0 \_} 1 \mathrm{~h}$ & $\mathrm{CMS}_{0 \_} 3 \mathrm{~h}$ \\
\hline MTES $_{0.1}$ & CMS & $\mathrm{CMS}_{0.1-1 \mathrm{~h}}$ & $\mathrm{CMS}_{0.1-1} 3 \mathrm{~h}$ \\
\hline MTES $_{0.5}$ & & $\mathrm{CMS}_{0.5-} 1 \mathrm{~h}$ & $\mathrm{CMS}_{0.5-} 3 \mathrm{~h}$ \\
\hline $\mathrm{PTES}_{0}$ & & $\mathrm{CPS}_{0 \_} 1 \mathrm{~h}$ & $\mathrm{CPS}_{0 \_} 3 \mathrm{~h}$ \\
\hline $\mathrm{PTES}_{0.1}$ & CPS & $\mathrm{CPS}_{0.1-1 \mathrm{~h}}$ & $\mathrm{CPS}_{0.1-} 3 \mathrm{~h}$ \\
\hline PTES $_{0.5}$ & & $\mathrm{CPS}_{0.5-} 1 \mathrm{~h}$ & $\mathrm{CPS}_{0.5-} 3 \mathrm{~h}$ \\
\hline VTMS $_{0}$ & & $\mathrm{CVS}_{0 \_} \_\mathrm{h}$ & $\mathrm{CVS}_{0 \_} 3 \mathrm{~h}$ \\
\hline $\operatorname{VTMS}_{0.1}$ & CVS & $\mathrm{CVS}_{0.1} \_1 \mathrm{~h}$ & $\mathrm{CVS}_{0.1-3} 3 \mathrm{~h}$ \\
\hline VTMS $_{0.5}$ & & $\mathrm{CVS}_{0.5 \_} 1 \mathrm{~h}$ & $\mathrm{CVS}_{0.5-} 3 \mathrm{~h}$ \\
\hline
\end{tabular}


and different annealing times plays an important role to investigate the production and growth of $\mathrm{C}$ and $\mathrm{SiC}$ phases under boron influence.

\section{Characterization techniques}

\section{Thermogravimetry (TG)}

Thermal stability of preceramic precursors was evaluated on a thermogravimetric analyzer (TGA, 4000, PerkinElmer, Tokyo, Japan) employing a temperature range from 25 to $900{ }^{\circ} \mathrm{C}$, at $10{ }^{\circ} \mathrm{C} \mathrm{min}{ }^{-1}$ and nitrogen flowing of $20 \mathrm{~mL} \mathrm{~min}^{-1}$. Thermogravimetric measurements were conducted with ca. $10 \mathrm{mg}$ of samples and the ceramic yield was obtained by residual mass percentage at final temperature of $800^{\circ} \mathrm{C}$.

\section{Fourier transform-infrared spectroscopy (FTIR)}

FTIR spectra of the preceramic polymers and ceramics based on SiOC and SiBOC systems were acquired on a Fourier transform infrared spectrometer (IR Prestige-21, Shimadzu, Tokyo, Japan), between 4000 and $400 \mathrm{~cm}^{-1}$, with spectral resolution of $4 \mathrm{~cm}^{-1}$ and 16 scans. Powdered samples were mixed with $\mathrm{KBr}$ pellets and analyzed in the transmittance operation mode.

\section{$\mathrm{X}$-ray diffraction $(\mathrm{XRD})$}

$\mathrm{X}$-ray diffractograms of the $\mathrm{SiOC}$ and $\mathrm{SiBOC}$ ceramics were obtained on an X-ray diffractometer (PANanalytical, X'Pert PRO MPD, Malvern Panalytical, Almelo, Netherlands) operating with $\mathrm{Cu} \mathrm{K} \alpha$ radiation ( $\lambda=1.54060 \AA$ ), using the $\theta-2 \theta$ technique, Bragg Brentano geometry at $40 \mathrm{kV}$ and $30 \mathrm{~mA}$. XRD patterns were collected between 5 and $80^{\circ}(2 \theta)$, with $0.04^{\circ}$ step size at $2.0 \mathrm{~s}$. To avoid preferred orientations in the sample preparation process, the powdered samples were rotated cyclically during measurements with a period of $1.0 \mathrm{~s}$.

The average crystallite size ( $\mathrm{t}$ ) for $\mathrm{SiC}$ phase was calculated by the Scherrer formula according to equation $5 .{ }^{46}$

$\mathrm{t}=\frac{\mathrm{K} \cdot \lambda}{\beta \cdot \cos \theta}$

where $t$ is assigned to the average crystallite size, $\lambda$ is the radiation wavelength in nanometers $(0.15406 \mathrm{~nm}), \beta$ is the width at half height of the diffraction signal in radians, $\theta$ corresponds to half of the $2 \theta$ angle and $\mathrm{K}$ is a constant that depends on the particle morphology and ranges from 0.89 to $1.39 \mathrm{rad}$. As the crystallites obtained in this study have no defined shape, we employed $\mathrm{K}=1$, which corresponds to an apparent average volume size regardless of specific morphology. ${ }^{29-31}$

\section{X-ray photoelectron spectroscopy (XPS)}

X-ray photoelectron spectroscopy (XPS) measurements were carried out for the $\mathrm{SiOC}$ and $\mathrm{SiBOC}$ ceramics on a spectrometer (Escalab 250Xi, Surface Analysis Thermo Fischer Scientific, East Grinstead, UK) employing Al K $\alpha$ radiation of $1486.6 \mathrm{eV}$ and survey power of $100 \mathrm{eV}$. The overall instrumental resolution was about $25 \mathrm{eV}$. The data were collected by means of an Avantage Data Acquisition and Processing software.

\section{Results and Discussion}

SiOC and SiBOC preceramic precursors: macroscopic appearances and characteristics

Preceramic polymers containing methyl-, phenyl- and vinyl-modified alkoxysilanes were synthesized by the solgel method, resulting in nine samples, which presented distinct macroscopic appearances, as can be seen in Table 3 .

Table 3. Reaction and gelation times for each prepared preceramic precursor together with corresponding macroscopic appearance after polymerization reaction by the sol-gel method

\begin{tabular}{lccc}
\hline $\begin{array}{l}\text { Preceramic } \\
\text { precursor }\end{array}$ & $\begin{array}{c}\text { Reaction } \\
\text { time / min }\end{array}$ & $\begin{array}{c}\text { Gelation } \\
\text { time / days }\end{array}$ & Macroscopic appearance \\
\hline MTES $_{0}$ & 15 & 3 & transparent \\
MTES $_{0.1}$ & 1440 & 4 & white, opaque, vitreous \\
MTES $_{0.5}$ & 1800 & 4 & white, opaque, vitreous \\
PTES $_{0}$ & 15 & 3 & white, crystalline \\
PTES $_{0.1}$ & 1800 & 7 & white, opaque, chalk aspect \\
PTES $_{0.5}$ & 2160 & 15 & white, opaque, chalk aspect \\
VTMS $_{0}$ & 15 & 2 & vitreous, yellow colorless \\
VTMS $_{0.1}$ & 120 & 3 & opaque, brown colorless \\
VTMS $_{0.5}$ & 180 & 3 & opaque, brown \\
\hline
\end{tabular}

Reaction and gelation times increased with the boron content irrespective of the precursor, with less pronounced influence for gelation time by considering the set of MTES and VTMS samples. However, Sorarù et al ${ }^{28}$ verified a contrary trend for gelation time related to the preparation of methyl-, vinyl- and ethyl-triethoxysilane-derived borosilicate gels. Boric acid participates of dissolution step, promoting the formation of the siloxane network, and behaves as a crosslinking agent. Similar results during the synthesis of poly(borosiloxane) gels from methyltriethoxysilane and boric acid, with $\mathrm{B} / \mathrm{Si}$ atomic ratios of 0.2 and 0.5 , were also obtained by Siqueira et al. ${ }^{33}$

Indeed, both increasing and decreasing trends of gelation times regarding boron content had already been reported. ${ }^{37}$ According to Sorarù et al. ${ }^{38}$ when boron is inserted into alkoxysilane-derived polymeric structure 
via $\mathrm{B}(\mathrm{OSi})_{3}$ units, it behaves as a network former, with a reduction of the gelation times compared with the corresponding B-free polymeric gels. However, if the boron enters the polymeric network as non-bridging $\mathrm{B}(\mathrm{OH})_{3}$ units, it behaves as an inert compound that dilutes the solution, decreasing the reaction rates and, consequently, resulting in longer gelation times.

By comparing the same boron content, reactions and gelling process were faster for VTMS- followed by MTESand PTES-derived precursors. This behavior might be associated to steric hindrance promoted by the different organic groups during the hydrolysis and condensation reactions. ${ }^{28}$

In the overall, B-free precursors were monolithic and transparent, meanwhile they became opaque as well as denser aspect with increasing of boron amount. A qualitative comparison among the three set of alkoxysilanes precursors revealed that those derived from PTES exhibited less stiffness. Probably, the steric hindrance promoted by the bulky phenyl groups resulted in lower crosslinking density giving rise to a softer polymer structure. VTMS-derived precursors exhibited higher stiffness when compared to the other samples. Macroscopically, this evidence suggests that vinyl groups allowed a more effective crosslinking of polymeric network.

\section{Chemical structure}

Polymerization reaction by the sol-gel method involving methyl-, phenyl- and vinyl-alkoxysilanes in the presence and absence of boric acid gave rise to the respective $\mathrm{SiBOC}$ and $\mathrm{SiOC}$ preceramic precursors, named poly(borosiloxanes) and poly(organosiloxanes), as represented in Figure 1.

Synthesis of poly(borosiloxanes) precursors from alkoxysilanes and boric acid (Figure 1a) is based on the ability of $\mathrm{B}(\mathrm{OH})_{3}$ species to hydrolyze the $\mathrm{Si}-\mathrm{OR}$ groups producing reactive $\mathrm{Si}-\mathrm{OH}$ moieties which can condense with $\mathrm{B}-\mathrm{OH}$ bonds. As a result, boron atoms enter the siloxane network as trigonal $\mathrm{BO}_{3}$ units via stable $\mathrm{Si}-\mathrm{O}-\mathrm{B}$ bonds. ${ }^{26,28,31}$ Furthermore, B-OH bonds can directly condense with $\mathrm{Si}-\mathrm{OR}$ groups forming borosiloxane bonds and the corresponding alcohol molecule, $\mathrm{ROH}$ (methyl and ethyl alcohols in this case). ${ }^{40}$

Preparation of poly(organosiloxane) precursors from alkoxysilanes initially involved the hydrolysis step catalyzed by acid medium, in which $\mathrm{Si}-\mathrm{OR}$ groups are hydrolyzed to $\mathrm{Si}-\mathrm{OH}$ silanol groups. Following, condensation occurred among the silanol groups formed generating a tridimensional inorganic network composed of $\mathrm{Si}-\mathrm{O}-\mathrm{Si}$ siloxane bonds, remaining the presence of organic group, $\mathrm{R}=$ methyl, phenyl or vinyl (Figure $1 \mathrm{~b}$ ).

\section{Structural and thermal characterization}

\section{Fourier transform-infrared spectroscopy (FTIR)}

FTIR spectra for each preceramic precursor system in the presence and absence of different $\mathrm{B} / \mathrm{Si}$ atomic ratios are illustrated in Figure 2.

Broad absorption bands between 1200 and $1000 \mathrm{~cm}^{-1}$ $(v \mathrm{Si}-\mathrm{O}-\mathrm{Si})$ and around $460-400 \mathrm{~cm}^{-1}(\delta \mathrm{Si}-\mathrm{O}),{ }^{47}$ typical of inorganic siloxane network, were verified for all precursors. Organic groups bonded to $\mathrm{Si}$ gave rise to bands highlighted in Figure 2 as \# for $\mathrm{Si}-\mathrm{Me}, *$ for $\mathrm{Si}-\mathrm{Ph}$ and o for $\mathrm{Si}-\mathrm{Vi}$. The assignments and corresponding wavenumbers are reported in Table $4 .{ }^{28} \mathrm{~B}$-containing MTES-derived precursors revealed bands at $1300-1500,1195$ and $540 \mathrm{~cm}^{-1}$, assigned to $v \mathrm{~B}-\mathrm{O}$, $\delta \mathrm{B}-\mathrm{OH}$ and $\delta \mathrm{O}-\mathrm{B}-\mathrm{O},{ }^{40}$ respectively. Furthermore, the most important band at $880 \mathrm{~cm}^{-1}$ is attributed to $\mathrm{Si}-\mathrm{O}-\mathrm{B}$ bridges in the polymer structure. B-containing PTES- and VTMSderived precursors exhibited only some absorption bands corresponding to B-containing bonds (Figures $2 \mathrm{~b}$ and $2 \mathrm{c}$ ). (a)

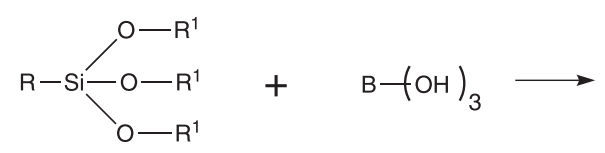

(b)

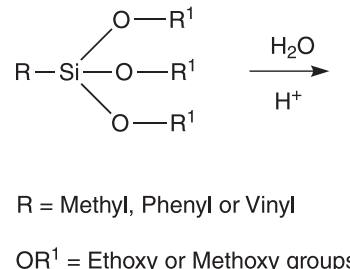

\footnotetext{
$\mathrm{OR}^{1}=$ Ethoxy or Methoxy groups
}

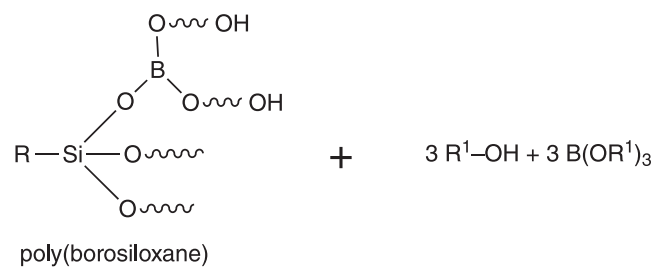

$$
\overbrace{\text { poly(organosiloxane) }}^{\mathrm{O}-\mathrm{Si}-\mathrm{O} \sim \mathrm{OH}}+3 \mathrm{R}^{1}-\mathrm{OH}+3 \mathrm{H}_{2} \mathrm{O}
$$

Figure 1. Proposed reactions by the sol-gel method illustrating the chemical structures for poly(borosiloxane) and poly(organosiloxane) preceramic precursors obtained with (a) and without (b) boric acid using methyl-, phenyl- and vinyl-alkoxysiloxanes. 
(a)

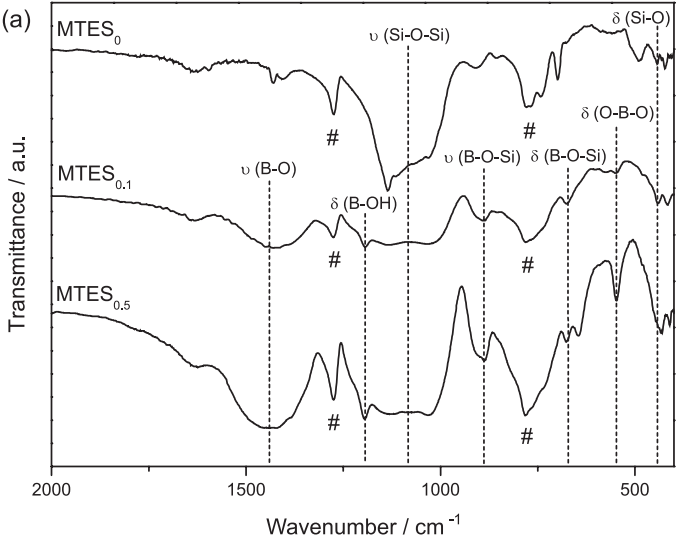

(b)

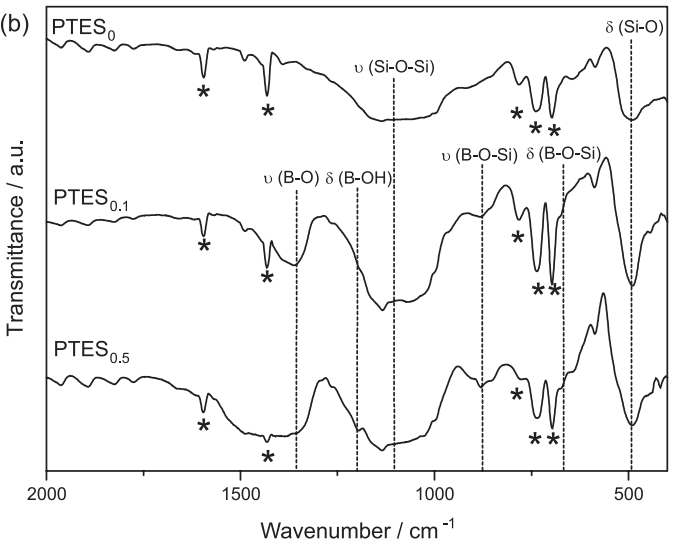

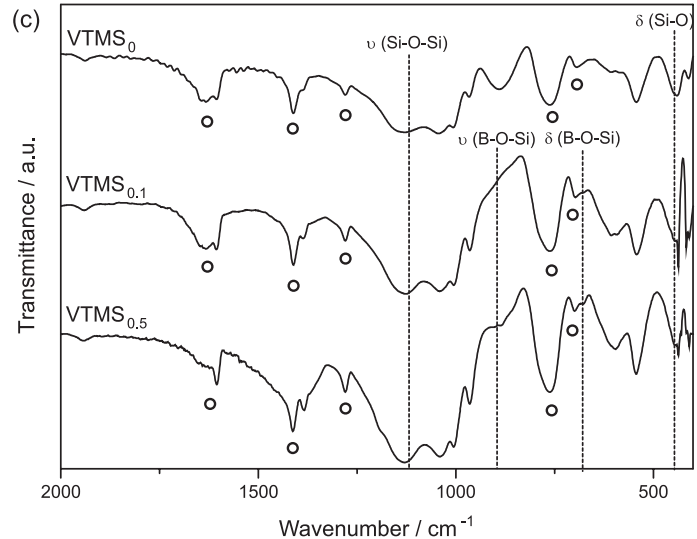

Figure 2. FTIR ( $\mathrm{KBr}$ ) spectra of preceramic precursors obtained by the sol-gel method from MTES (a), PTES (b) and VTMS (c), containing B/Si atomic ratios of $0,0.1$ and 0.5 .

During the precursor's synthesis, particularly in gelling and drying steps, boron compounds evaporation usually takes place, decreasing the boron amount in the final polymeric gel, thus justifying the absence or smaller intensities bands. ${ }^{26,48}$ According to spectral profiles, by comparing the original absorption bands intensities, it seems that MTES precursors exhibited more intense bands corresponding to B-containing bonds when compared to other samples. This trend suggests that $\mathrm{B}-\mathrm{O}-\mathrm{Si}$ bonds were preferentially formed in the methyl groups-containing borosilicate gels.

A comparison involving different $\mathrm{B} / \mathrm{Si}$ ratios in all alkoxysilanes-derived precursors revealed that the absorption band at around $880 \mathrm{~cm}^{-1}$, assigned to borosiloxane bridges, increased with the $\mathrm{B}$ content. This result indicated that more trigonal boron units, composed of $\mathrm{BO}_{3}$, were incorporated into siloxane networks with increasing of boric acid amount ${ }^{28}$ and this behavior was more evident for MTES-derived precursors and less pronounced for the VTMS system.

\section{Thermogravimetry (TG)}

Figure 3 displays TG curves for each preceramic precursor system in the presence and absence of different $\mathrm{B} / \mathrm{Si}$ atomic ratios.
Table 4. FTIR absorption bands and respective assignments associated to the presence of organic groups bonded to $\mathrm{Si}$ in the MTES, PTES and VTMS preceramic precursors

\begin{tabular}{lcc}
\hline $\begin{array}{l}\text { Preceramic precursors } \\
\text { system }\end{array}$ & Wavenumber $/ \mathrm{cm}^{-1}$ & Assignment \\
\hline \multirow{2}{*}{ MTES } & 1274 & $v\left(\mathrm{Si}-\mathrm{CH}_{3}\right)$ \\
& 775 & $v(\mathrm{Si}-\mathrm{C})$ \\
\hline \multirow{2}{*}{ PTES } & 1596 & $v(\mathrm{C}=\mathrm{C})$ \\
& 1431 & $v(\mathrm{Si}-\mathrm{Ph})$ \\
& 738 & $\delta(\mathrm{Si}-\mathrm{Ph})$ \\
& 787 & $v(\mathrm{Si}-\mathrm{C})$ \\
& 699 & $\delta(\mathrm{Si}-\mathrm{Ph})$ \\
\hline \multirow{3}{*}{ VTMS } & 1630 & $v(\mathrm{C}=\mathrm{C})$ \\
& 1412 & $v\left(\mathrm{Si}-\mathrm{CH}=\mathrm{CH}{ }_{2}\right)$ \\
& 1280 & $v(\mathrm{Si}-\mathrm{CH})$ \\
& 757 & $v(\mathrm{Si}-\mathrm{C})$ \\
& 693 & $\rho\left(\mathrm{Si}-\mathrm{CH}{ }_{2}\right)$ \\
\hline
\end{tabular}

MTES: methyltriethoxysilane; PTES: phenyltriethoxysilane; VTMS: vinyltrimethoxysilane.

In general, boron-free precursors revealed similar thermogravimetric profiles regarding to boron-containing samples and four main degradation steps were observed, with exception to PTES-derived precursors, which 

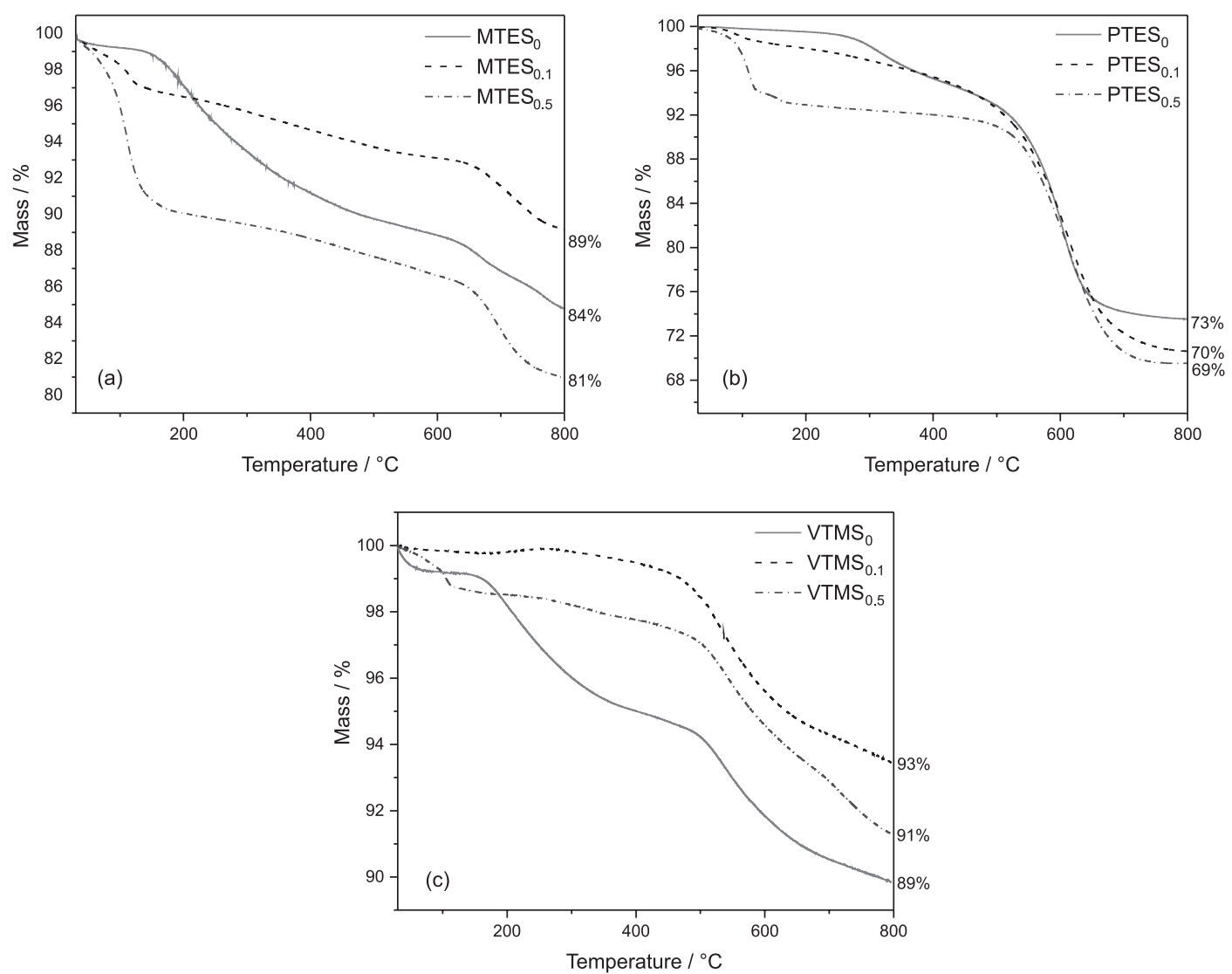

Figure 3. TG curves of preceramic precursors obtained by the sol-gel method from MTES (a), PTES (b) and VTMS (c), containing B/Si atomic ratios of $0,0.1$ and 0.5 .

displayed three thermal decomposition events. The first event, occurred from room temperature to $150^{\circ} \mathrm{C}$, is related to evolution of water and alcohols, whilst the second evident event, from 150 to $300-400{ }^{\circ} \mathrm{C}$, is attributed to evolution of free oligomers trapped in polymer structure, structural water, ethanol and methanol resulting of condensation reactions involving residual $\mathrm{Si}-\mathrm{OH}, \mathrm{Si}-\mathrm{OEt}, \mathrm{Si}-\mathrm{OMe}$ and $\mathrm{B}-\mathrm{OH}$ moieties and initial decomposition of organic groups. ${ }^{26,41}$ Furthermore, volatile boron compounds as well as boric acid molecules, that did not react during polymerization reaction, were also released in this temperature range. ${ }^{35}$ The third less evident step, in the temperature range from $300-400$ until $600{ }^{\circ} \mathrm{C}$, is assigned to redistribution reactions between $\mathrm{Si}-\mathrm{O}$ and $\mathrm{Si}-\mathrm{C}$ bonds, releasing low molar mass oligomers and cyclic siloxanes. ${ }^{26}$ The evident fourth step, occurred from 600 to $800{ }^{\circ} \mathrm{C}$, is related to the polymer-to-ceramic conversion with the formation of corresponding silicon oxycarbide (SiOC) and boron silicon oxycarbide ( $\mathrm{SiBOC}$ ) glasses. This step is also associated with the cleavage of $\mathrm{C}-\mathrm{H}$ and $\mathrm{Si}-\mathrm{C}$ bonds, leading to the evolution of hydrogen and low molar mass hydrocarbons. ${ }^{26,30}$

As expected, the initial mass loss was more pronounced for B-containing samples when compared to B-free samples, due to boron compounds evolution, and this trend was proportional to boron amount. Considering the intermediary temperature range, the boron addition increased the thermal stability of polymer, indicating that boron atoms were incorporated into siloxane network. However, higher B contents revealed an opposite behavior for MTES $_{0.5}$ and PTES ${ }_{0.5}$ samples. Probably, the less effective incorporation of boron for these respective systems are related to the absence of additional crosslinking and formation of a more opened polymeric network, as further described, which favored the greater evolution of boron compounds.

While PTES-derived precursors presented practically the same ceramic yield values, as shown at the last point of TG curves (Figure $3 b$ ), samples with $\mathrm{B} / \mathrm{Si}=0.1$ exhibited higher values with respect to pure precursors for both MTES and VTMS systems (Figures $3 \mathrm{a}$ and $3 \mathrm{c}$ ). The lowest ceramic yield values for $\mathrm{B} / \mathrm{Si}=0.5$ are due to the more intense boron losses at low temperatures, as already stated. ${ }^{33}$ By comparing the different sets of polymeric systems, the following decreasing order for ceramic yields was achieved, VTMS- > MTES- > PTES-derived precursors. The highest ceramic yield values for VTMS system were attributed to the polymerization of Si-vinyl groups during heat treatment, 
resulting in additional crosslinking and, consequently, a more interconnected polymeric network. ${ }^{26,49}$

Thermogravimetric profiles for PTES system, mainly regarding to third step occurred from 500 to $750{ }^{\circ} \mathrm{C}$ (Figure $3 b$ ), suggested a more opened network owing to empty spaces generated by the aromatic rings in the polymer structure. As consequence, more pronounced mass losses and less densely crosslinked precursors were obtained, in agreement with the macroscopic appearances (Table 3). However, the slower and continuous degradation of polymeric structure for both MTES and VTMS systems indicated that more packed polymeric networks were produced. Indeed, the highest ceramic yields for VTMS system (Figure $3 \mathrm{c}$ ) together with the additional crosslinking promoted by the Si-vinyl groups justified the higher stiffness macroscopically observed.

\section{Characterization of $\mathrm{SiOC}$ and $\mathrm{SiBOC}$ ceramic materials}

\section{Fourier transform-infrared spectroscopy (FTIR)}

Figure 4 exhibits FTIR spectra of SiOC and SiBOC ceramics derived from MTES, PTES and VTMS precursors (CMS, CPS and CVS ceramics), obtained at $1500{ }^{\circ} \mathrm{C}$ during 1 and $3 \mathrm{~h}$ annealing times. All ceramics presented spectral profiles typical of mineralized materials, evidenced by the absence of bands assigned to organic groups from alkoxysilanes precursors and presence of absorption bands corresponding to inorganic bonds. Broad bands at around 1086, 818 and $460 \mathrm{~cm}^{-1}$, attributed to $v \mathrm{Si}-\mathrm{O}-\mathrm{Si}$, $\nu \mathrm{Si}-\mathrm{C}$ and $\delta \mathrm{Si}-\mathrm{O},{ }^{32}$ respectively, are typical of siloxane ceramic network, which were verified with different relative intensities according to each ceramic system. More intense bands at $818 \mathrm{~cm}^{-1}(v \mathrm{Si}-\mathrm{C})$ with respect to those at $1086 \mathrm{~cm}^{-1}(v \mathrm{Si}-\mathrm{O}-\mathrm{Si})$ were mainly verified for the set of CPS ceramics, suggesting more effective phase segregation into ceramic matrix with the $\mathrm{SiC}$ formation, as expected after pyrolysis at $1500{ }^{\circ} \mathrm{C} .{ }^{50,51}$ This trend, more evident for CPS ceramics, might be explained by the higher $\mathrm{C}_{\text {free }}$ amounts produced during heating treatment upon inert atmosphere for phenyl groups-containing precursors when compared to methyl and vinyl groups. Usually, inorganic precursors with aromatic and unsaturated organic groups attached at siloxane chain produce by degradation higher $\mathrm{C}_{\text {free }}$ contents in relation to saturated organic groups, giving rise to more effective production of $\mathrm{SiC}$ phase via carbothermal reduction reaction (equation 4).$^{52}$ Effect of carbon content on structural properties of silicon carbon nitride $(\mathrm{SiCN})$ was studied by atomistic simulations. ${ }^{53}$ Indeed, the resulting structures showed a tendency to include a free carbon phase with increasing of the carbon content. Carbon rich regions became larger, resulting in a network as the carbon content increases, as similarly verified in $\mathrm{SiCO}$ matrices. Further information on the local structure was provided by the $\mathrm{Si}-\mathrm{N}-\mathrm{Si}$ and $\mathrm{C}-\mathrm{C}-\mathrm{C}$ angular distributions, whose results indicated variations of $\mathrm{Si}-\mathrm{C}$ bonds near the graphene layers when the sizes of carbon phases change. The proposed atomic model was employed to predict the structural as well as mechanical properties of $\mathrm{SiCN}$ materials at different compositions.

In general, B-containing ceramics revealed bands at ca. $1639,1400,887$ and $680 \mathrm{~cm}^{-1}$, related to the respective $\mathrm{B}-\mathrm{O}-\mathrm{B}$ bonds, $v \mathrm{~B}-\mathrm{O}, v \mathrm{~B}-\mathrm{O}-\mathrm{Si}$ and $\delta \mathrm{B}-\mathrm{O}-\mathrm{Si}^{32}$ These bands were more evident for CMS ceramics followed by the CPS and CVS systems, in agreement with the spectra profiles observed for the corresponding preceramic precursors (Figure 2), which suggested more effective boron incorporation for methyl-, phenyl- and vinyl-derived materials. Vibrational modes assigned to $\mathrm{B}-\mathrm{O}$ and $\mathrm{B}-\mathrm{O}-\mathrm{Si}$ bonds, although less evident in some FTIR spectra, are probably associated to the redistribution reaction (equation 6) between $\mathrm{B}-\mathrm{C}$ and $\mathrm{Si}-\mathrm{O}$ bonds favored at high temperatures. ${ }^{30}$

$\mathrm{B}-\mathrm{C}+\mathrm{Si}-\mathrm{O} \rightarrow \mathrm{B}-\mathrm{O}+\mathrm{Si}-\mathrm{C}$

Apparently, more intense bands attributed to B-containing bonds were not verified with increasing boron content. Some bands related to borosiloxane bonds might be overlapped or a considerable portion of boron compounds was evaporated during the heating treatment at high temperatures ${ }^{48}$ preventing their visualization by FTIR technique.

\section{X-ray diffraction (XRD)}

Effect of boron content, organic substituent and annealing time on phase development of all ceramics was evaluated by X-ray diffraction, according to XRD patterns displayed in Figure 5.

CMS ceramics annealed for $1 \mathrm{~h}$ at $1500^{\circ} \mathrm{C}$ (Figure 5a) revealed broad haloes at ca. $12^{\circ}$ and $24^{\circ}(2 \theta)$, corresponding to a low ordering degree $(+)$ and a random array of mixed silicon oxycarbide $\left(\mathrm{SiO}_{\mathrm{x}} \mathrm{C}_{4-\mathrm{x}}, 1 \leq \mathrm{x} \leq 3\right)$ and boron oxycarbide $\left(\mathrm{BO}_{\mathrm{y}} \mathrm{C}_{3-\mathrm{y}}, 1 \leq \mathrm{y} \leq 2\right)$ units (\#) from respective $\mathrm{SiOC}$ and $\mathrm{SiBOC}$ ceramics. ${ }^{20,34}$ Broad diffraction signals at $35.5,60$ and $72^{\circ}(2 \theta)$, typical of $\mathrm{SiC}$ phase, were also detected. ${ }^{31}$ These signals became sharper as boron content increased, indicating more effective $\mathrm{SiC}$ crystallization, mainly at $\mathrm{B} / \mathrm{Si}=0.5$. Furthermore, a broad hump around $43^{\circ}(2 \theta)$ assigned to the disordered carbon phase $(*)$ was identified, ${ }^{15}$ with lower evidence for $\mathrm{CMS}_{0.1} 1 \mathrm{~h}$ and $\mathrm{CMS}_{0.5}{ }_{-} 1 \mathrm{~h}$ when compared to $\mathrm{CMS}_{0 \_} 1 \mathrm{~h}$. This probably suggests a higher consumption of residual carbon to 
(a)
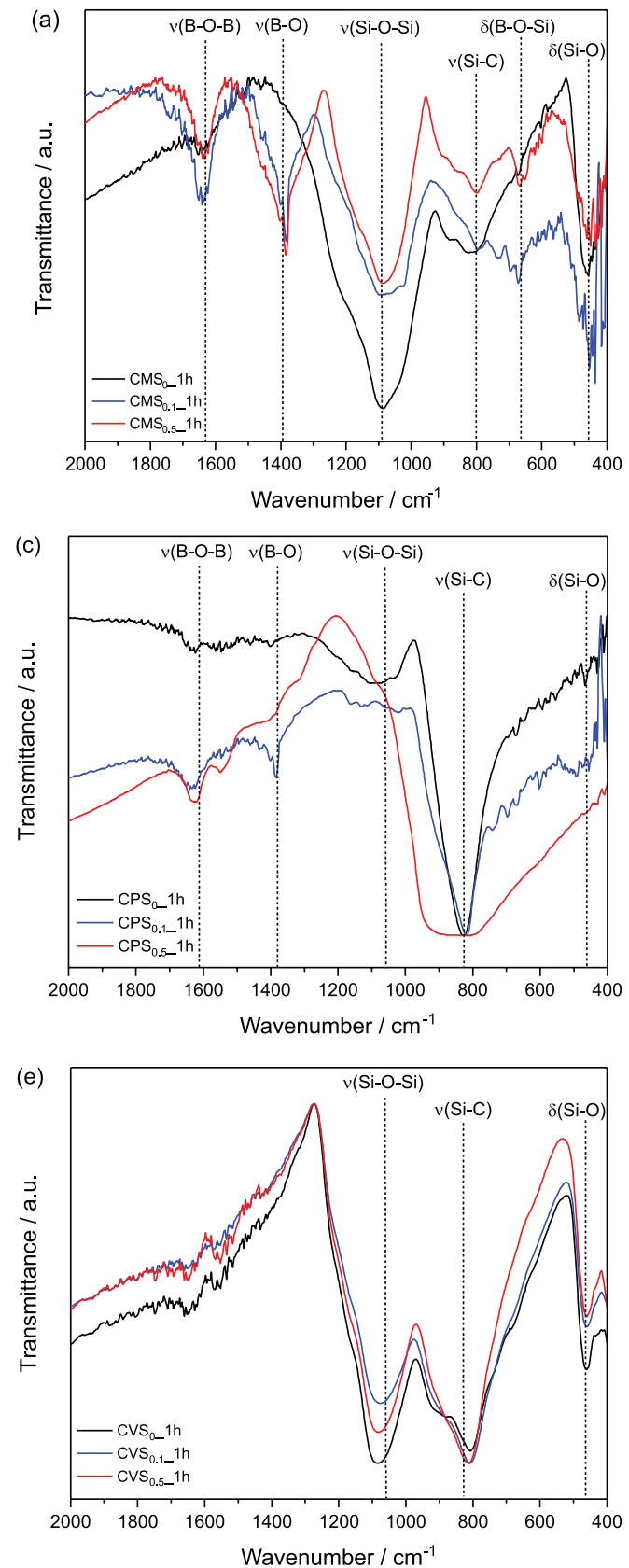
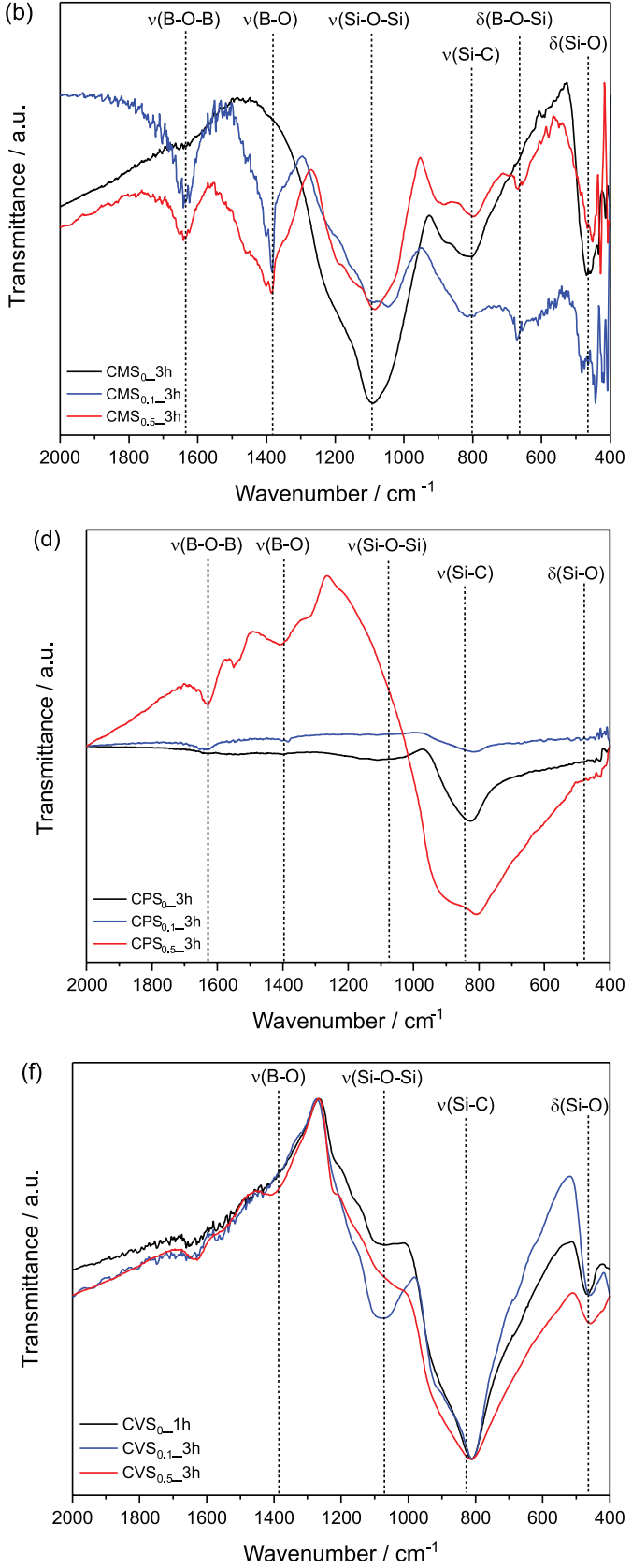

Figure 4. FTIR (KBr) spectra of CMS, CPS and CVS ceramics obtained by pyrolysis at $1500{ }^{\circ} \mathrm{C}$ during $1 \mathrm{~h}$ of the respective MTES-, PTES- and VTMSderived precursors with $\mathrm{B} / \mathrm{Si}$ atomic ratios of $0,0.1$ and 0.5 (a, c and e) and after $3 \mathrm{~h}$ annealing (b, $\mathrm{d}$ and $\mathrm{f}$ ).

produce $\mathrm{SiC}$ phase in the B-containing ceramics. Similar XRD patterns for corresponding CMS ceramics annealed for $3 \mathrm{~h}$ were obtained (Figure 5b), practically indicating no crystallinity changes according to the annealing times evaluated.

Considerable crystallinity enhancement was achieved for the set of CPS ceramics (Figures $5 \mathrm{c}$ and $5 \mathrm{~d}$ ) in relation to CMS ceramics (Figures 5a and 5b). Much sharper and intense peaks assigned to $\mathrm{SiC}$ phase, together with the disappearance of amorphous portions (halo at $2 \theta=24^{\circ}$ ) and pronounced diminishing of low ordering degree region (broad signal at $2 \theta=12^{\circ}$ ) were observed. Disordered carbon phase was also verified, which exhibited slightly sharper diffraction signals with boron content, indicating some graphitization degree. ${ }^{13}$ Graphitization of nanocrystalline graphite into $\mathrm{SiBOC}$ at $1500^{\circ} \mathrm{C}$, with the aid of boron, was reported by Peña-Alonso et al ${ }^{42}$ Literature $^{42}$ proposes that $\mathrm{C}$ atoms in the hexagonal graphene sheets are substituted by the $\mathrm{B}$ atoms resulting in $\mathrm{BC}_{3}$ units, despite its mechanism is not completely understood. Therefore, boron addition associated to the carbon available for CPS ceramics contributed to crystallization of the $\mathrm{SiC}$ and residual carbon 
(a)

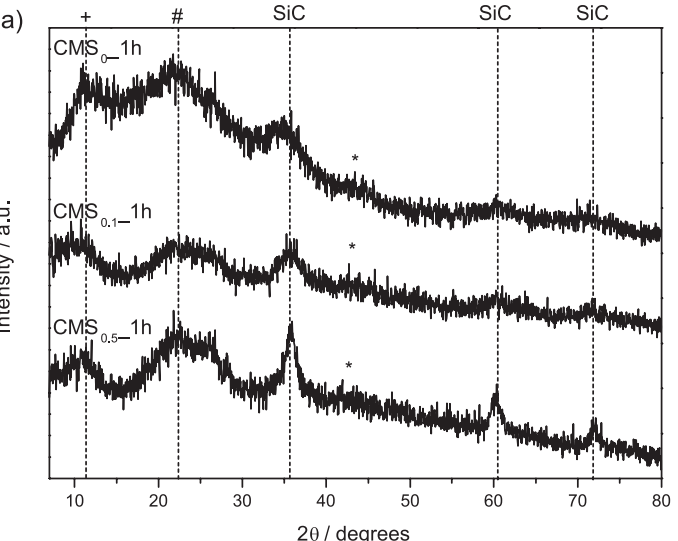

(c)

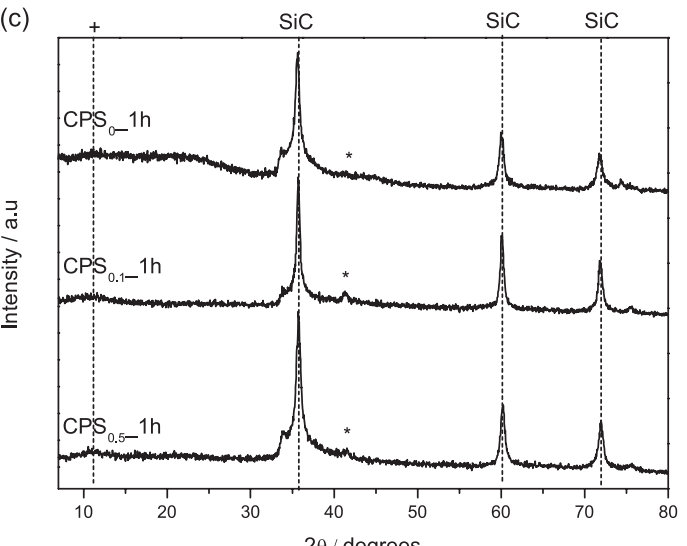

(e)

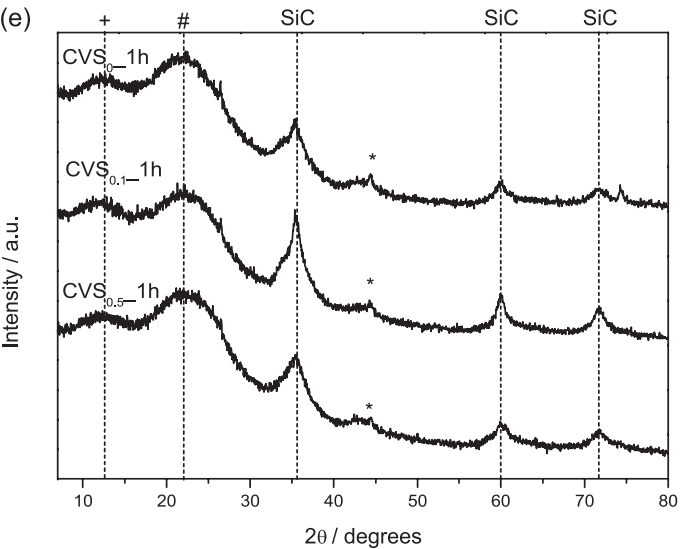

(b)

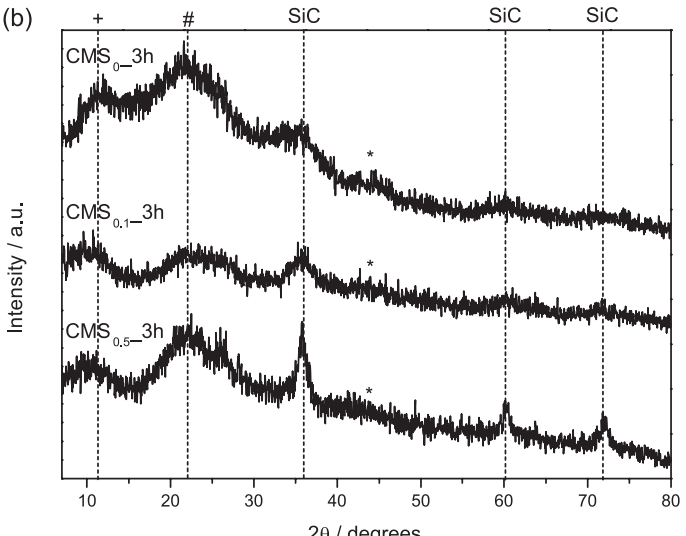

(d)

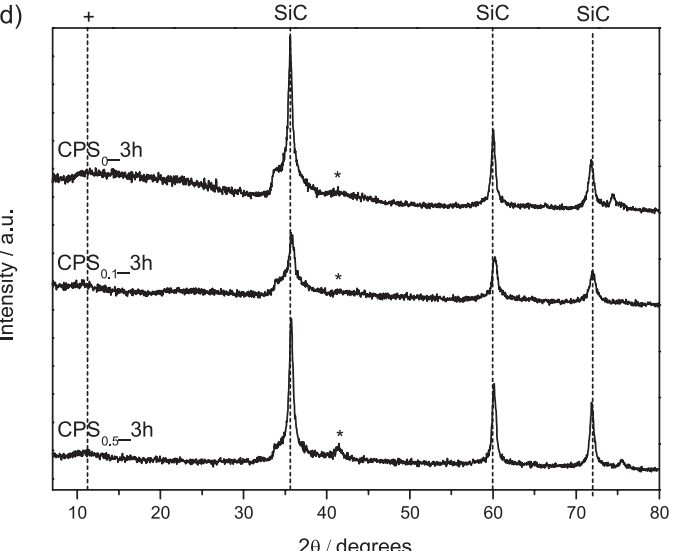

(f)

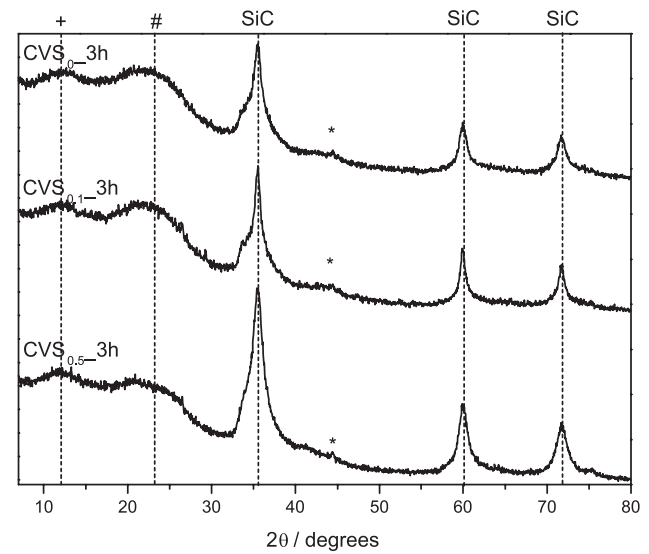

Figure 5. XRD patterns of CMS, CPS and CVS ceramics obtained by pyrolysis at $1500^{\circ} \mathrm{C}$ during $1 \mathrm{~h}$ of the respective MTES-, PTES- and VTMS-derived precursors with $\mathrm{B} / \mathrm{Si}$ atomic ratios of $0,0.1$ and 0.5 (a, c and e) and after $3 \mathrm{~h}$ annealing (b, d and f).

phases in different extent. A qualitative interpretation demonstrated no pronounced changes in XRD patterns, according to boron content and annealing time individually investigated, for CPS ceramics.

Intermediary crystallinity profiles for CVS ceramics (Figures 5e and 5f) were noticed by comparing the three ceramic systems. The same diffraction peaks and signals attributed to $\mathrm{SiC}$ and carbon phases as well as to amorphous and low ordering degree portions were detected, but with XRD patterns exactly comprised between CMS (Figures 5a and 5b) and CPS (Figures 5c and 5d) ceramics. It seems that boron amount, but mainly the annealing time contributed to a more effective growth of $\mathrm{SiC}$ phase in relation to the same comparison for the other two set of ceramic samples. ${ }^{32,34,54}$

A quantitative investigation over the different crystalline behaviors by considering the broadening line analysis, according to Scherrer equation, has been performed on the diffraction peak of $\mathrm{SiC}$ at $35.5^{\circ}(2 \theta)$ and allows to estimate their average crystallite sizes, as compiled in Table 5 for all ceramics prepared. 
Table 5. Average SiC crystallite sizes (t) values estimated from the broadening line analysis, according to Scherrer equation (equation 5$)^{45}$ on the diffraction peak at $35.5^{\circ}(2 \theta)$ for CMS, CPS and CVS ceramics with and without boron pyrolyzed at $1500{ }^{\circ} \mathrm{C}$ for 1 and $3 \mathrm{~h}$ isothermal annealing

\begin{tabular}{lc}
\hline Ceramic material & $\mathrm{t} / \mathrm{nm}$ \\
\hline $\mathrm{CMS}_{0 \_} 1 \mathrm{~h}$ & 0.87 \\
$\mathrm{CMS}_{0.1} 1 \mathrm{~h}$ & 2.63 \\
$\mathrm{CMS}_{0.5} 1 \mathrm{~h}$ & 7.44 \\
$\mathrm{CMS}_{0 \_} 3 \mathrm{~h}$ & 0.65 \\
$\mathrm{CMS}_{0.1} 3 \mathrm{~h}$ & 2.40 \\
$\mathrm{CMS}_{0.5-} 3 \mathrm{~h}$ & 7.72 \\
\hline $\mathrm{CPS}_{0-1} 1 \mathrm{~h}$ & 13.40 \\
$\mathrm{CPS}_{0.1} 1 \mathrm{~h}$ & 18.51 \\
$\mathrm{CPS}_{0.5-} 1 \mathrm{~h}$ & 13.81 \\
$\mathrm{CPS}_{0} 3 \mathrm{~h}$ & 14.01 \\
$\mathrm{CPS}_{0.1} 3 \mathrm{~h}$ & 11.42 \\
$\mathrm{CPS}_{0.5-} 3 \mathrm{~h}$ & 15.42 \\
\hline $\mathrm{CVS}_{0-} 1 \mathrm{~h}$ & 2.49 \\
$\mathrm{CVS}_{0.1} 1 \mathrm{~h}$ & 4.39 \\
$\mathrm{CVS}_{0.5-} 1 \mathrm{~h}$ & 4.94 \\
$\mathrm{CVS}_{0-} 3 \mathrm{~h}$ & 7.28 \\
$\mathrm{CVS}_{0.1} 3 \mathrm{~h}$ & 9.73 \\
$\mathrm{CVS}_{0.5} 3 \mathrm{~h}$ & 9.47 \\
\hline
\end{tabular}

Indeed, CPS ceramics presented the largest $\mathrm{SiC}$ crystallites, followed by the CVS and CMS ceramic systems, as earlier stated from XRD patterns (Figure 5). This trend might be explained by the different residual carbon $\left(\mathrm{C}_{\text {free }}\right)$ amounts produced after pyrolysis, according to the organic substituent at alkoxysilane precursor structure. It is expected the following decreasing order related to $\mathrm{C}_{\text {free }}$ contents as a function of organic groups: phenyl > vinyl $>$ methyl. ${ }^{37,55}$ Therefore, the higher carbon availability obtained in the phenyl groups-containing precursors possibly contributed to more effective production of $\mathrm{SiC}$ phase, resulting in larger nanocrystals, once carbon atoms in the neighboring of silicon atoms assist the formation of $\mathrm{Si}-\mathrm{C}$ bonds $^{56}$ as well as by carbothermal reduction reaction (equation 4). ${ }^{20,21}$ Phase separation and free carbon structures were successfully reproduced by melt-quench simulation into amorphous $\mathrm{SiBCO}$ materials with different carbon contents. ${ }^{25}$ An investigation of interface between free carbon and $\mathrm{Si}-\mathrm{O}$ region of certain $\mathrm{SiBCO}$ composition revealed that the $\mathrm{C}$ atoms of graphitic layers only connect to $\mathrm{Si}$ atoms, and $\mathrm{Si}$ atoms form mixed bonds to $\mathrm{C}$ and $\mathrm{O}$ atoms with a tetrahedra geometry. The increasing of carbon content increases the amount of tetrahedrons with high $\mathrm{C}$ percentage, while decreases the proportion of $\mathrm{Si}-\mathrm{O}_{4}$ tetrahedron, justifying the in situ formation of rich $\mathrm{Si}-\mathrm{C}$ bonds domains.
B-containing ceramics showed larger SiC nanocrystals compared to B-free ceramic samples. At high temperatures, typically around 1400 and $1500{ }^{\circ} \mathrm{C}$, the presence of $\mathrm{B}$ in the silicon oxycarbide materials favors the consumption of the mixed $\mathrm{Si}$ (and mixed $\mathrm{B}$ in $\mathrm{SiBOC}$ ) units, giving rise to a phase separation into $\mathrm{SiC}_{4}$ and borosilicate clusters. ${ }^{42}$ The proportional increasing of $\mathrm{SiC}$ nanocrystals as boron content increases was more pronounced for CMS, followed by the CVS ceramics. These ceramics revealed major contributions of amorphous character (Figures 5a-5b and 5e-5f) and, mainly a destabilization effect in the silicon oxycarbide network due to their lower $\mathrm{C}_{\text {free }}$ contents. ${ }^{56}$ Therefore, a more effective consumption of their mixed $\mathrm{Si}$ and $\mathrm{B}$ units probably took place, intensifying the boron action with the production of larger $\mathrm{SiC}$ nanocrystals. In contrast, non-proportional variations over crystallite sizes with the boron amount for CPS ceramics might be explained from their more crystalline profiles together with the higher free carbon amounts that stabilize the silicon oxycarbide structure at $1500{ }^{\circ} \mathrm{C},{ }^{56}$ directly influencing the boron acting mechanism.

In the overall trend, larger $\mathrm{SiC}$ crystallites for ceramics annealed at $1500{ }^{\circ} \mathrm{C}$ during $3 \mathrm{~h}$ were obtained, with emphasis for CVS ceramics, despite some samples revealed an opposite result (Table 5). Sorarù et al. ${ }^{57}$ investigated the effect of annealing at $1400{ }^{\circ} \mathrm{C}$ on the structural evolution of porous C-rich silicon(boron) oxycarbide glass. The authors obtained larger $\mathrm{SiC}$ crystallites (from $2.8 \pm 0.2$ to $3.5 \pm 0.2 \mathrm{~nm}$ ) and structural evolution of residual carbon phase, varying between turbostratic and graphitic structures, after holding times of 1 and $10 \mathrm{~h}$, respectively. The nanostructural evolution was justified by the phase separation process, which occurs in the $\mathrm{SiOC}$ ceramic matrix at higher temperatures, as represented in equation 1. Consumption of mixed silicon oxycarbide units $\left(\mathrm{SiO}_{\mathrm{x}} \mathrm{C}_{4-\mathrm{x}}, 1 \leq \mathrm{x} \leq 3\right)$, present in higher amounts in the $\mathrm{SiOC}$ structure at low temperature, i.e., $<1200{ }^{\circ} \mathrm{C}$, leads to a progressive increase of the $\mathrm{SiC}_{4}$ and $\mathrm{SiO}_{4}$ units, with subsequent progressive growth of the $\mathrm{SiC}$ nanocrystals, together with the ordering of the $\mathrm{C}_{\text {free }}$ phase. In this way, the opposite behaviors concerning $\mathrm{SiC}$ crystallite sizes verified for these B-containing and B-free ceramics might be related to the thermal degradation mechanisms and, subsequently, to phase separation processes occurred in structurally distinct precursors, producing silicon units in different extent.

\section{X-ray photoelectron spectroscopy (XPS)}

XPS measurements were carried out to get more insight into the chemical composition and bonding state on surface of the ceramic materials. All ceramics revealed peaks 
typical for O-based bond (O1s peak), C-based bond (C1s peak), Si-based bond (Si2s and Si2p peaks) and B-based bond (B1s peak), this latter for B-containing samples, ${ }^{58}$ which revealed different intensities according to ceramic system, boron content and annealing time, as illustrated in Figure 6.

$\mathrm{O} 1 \mathrm{~s}, \mathrm{C} 1 \mathrm{~s}, \mathrm{Si} 2 \mathrm{p}$ and $\mathrm{B} 1 \mathrm{~s}$ peaks fittings are given in Figures 7 and 8 for $\mathrm{CPS}_{0 \_} 1 \mathrm{~h}$ and $\mathrm{CPS}_{0.1}{ }_{-} 1 \mathrm{~h}$ samples, respectively, to illustrate the corresponding components of ceramics in the absence and presence of boron. Basically, O1s peak fitting revealed $\mathrm{O}-\mathrm{C}, \mathrm{O}-\mathrm{Si}, \mathrm{O}-\mathrm{C}=\mathrm{O}$ and $\mathrm{O}-\mathrm{B}$ bonds, whilst $\mathrm{C} 1$ s exhibited $\mathrm{Si}-\mathrm{C}$ and $\mathrm{C}-\mathrm{O}$ bonds as well as

(a)

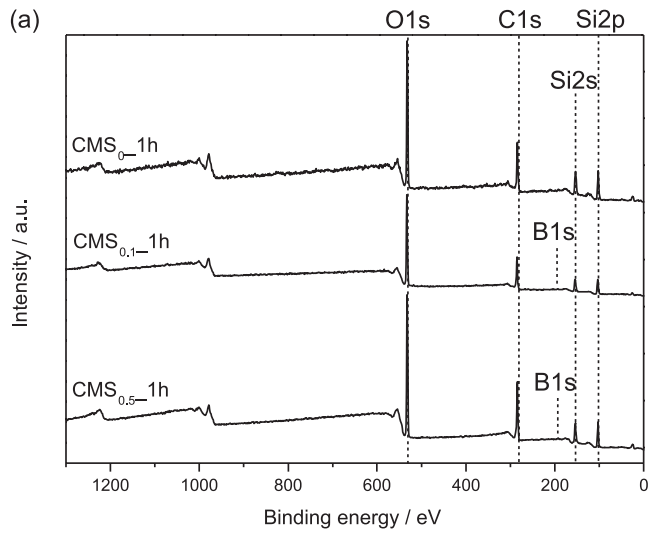

(c)

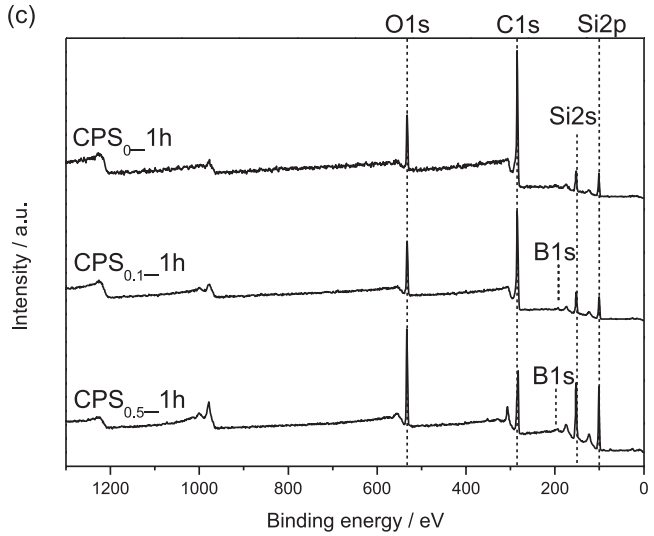

(e)

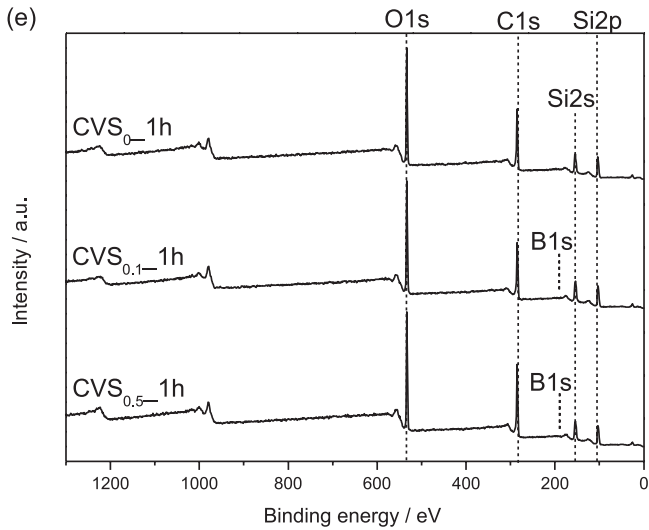

$\mathrm{Csp}^{3}$ and $\mathrm{Csp}^{2}$. Deconvoluted $\mathrm{Si} 2 \mathrm{p}$ and $\mathrm{B} 1 \mathrm{~s}$ peaks resulted in $\mathrm{Si}-\mathrm{C}, \mathrm{Si}-\mathrm{O}, \mathrm{SiO}_{2}, \mathrm{BC}_{2} \mathrm{O}, \mathrm{BCO}_{2}, \mathrm{BOSi}$ and $\mathrm{B}_{2} \mathrm{O}_{3}$ units. ${ }^{59}$

Percentages corresponding to $\mathrm{Csp}^{2}, \mathrm{Csp}^{3}$ and $\mathrm{C}_{\text {free }}$, together with $\mathrm{Si}-\mathrm{O}$ and $\mathrm{Si}-\mathrm{C}$ bonds and different trigonal boron units were determined by the deconvoluted $\mathrm{C} 1 \mathrm{~s}$, Si2p and B1s peaks integration for all ceramics, as shown in Table 6.

CPS ceramics revealed the highest and lowest percentages for $\mathrm{Si}-\mathrm{C}$ and $\mathrm{Si}-\mathrm{O}$ bonds, respectively, followed by CVS and CMS systems, confirming the enhanced crystallization for phenyl-groups containing samples by means of $\mathrm{SiC}$ phase production and simultaneous

(b)

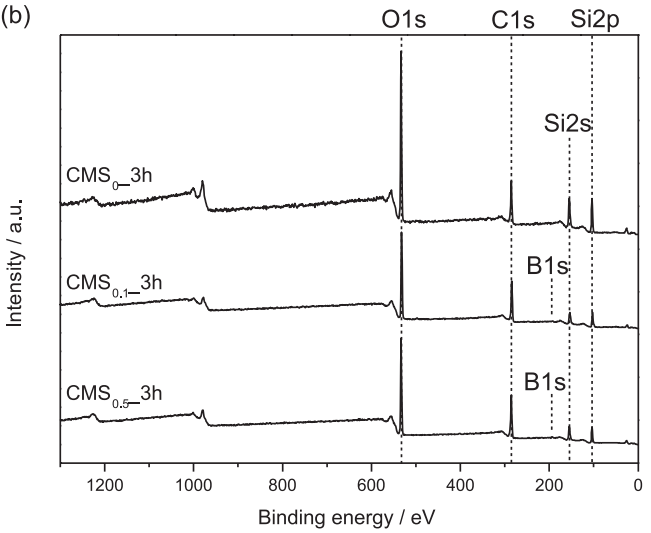

(d)

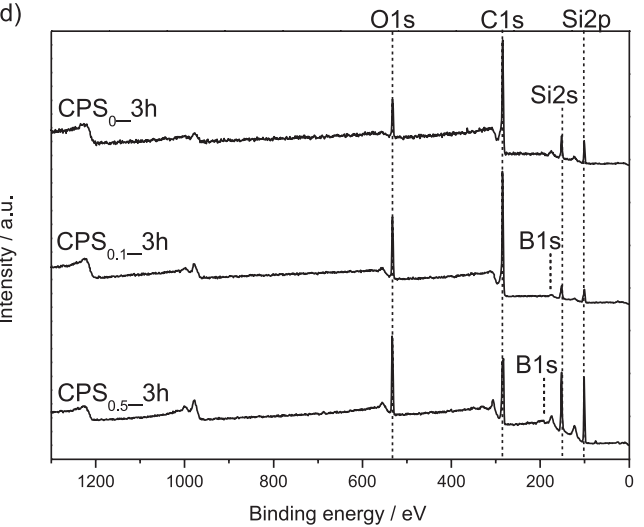

(f)

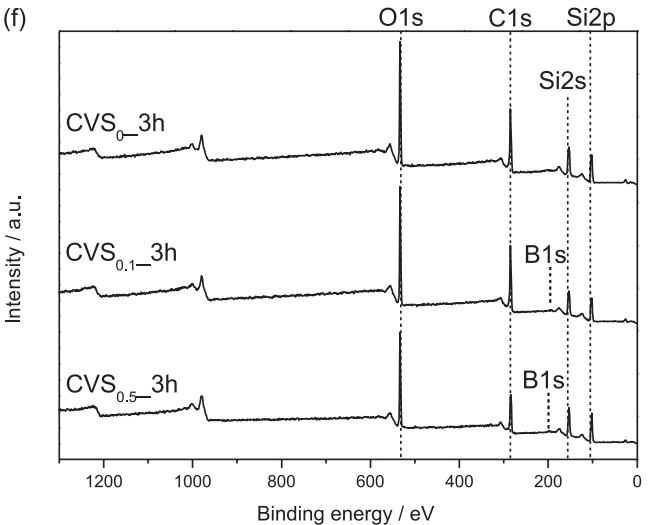

Figure 6. XPS survey spectra of CMS, CPS and CVS ceramics obtained by pyrolysis at $1500{ }^{\circ} \mathrm{C}$ during $1 \mathrm{~h}$ with $\mathrm{B} / \mathrm{Si}$ atomic ratios of $0,0.1$ and 0.5 (a, $\mathrm{c}$ and $\mathrm{e}$ ) and after $3 \mathrm{~h}$ annealing (b, $\mathrm{d}$ and $\mathrm{f}$ ). 

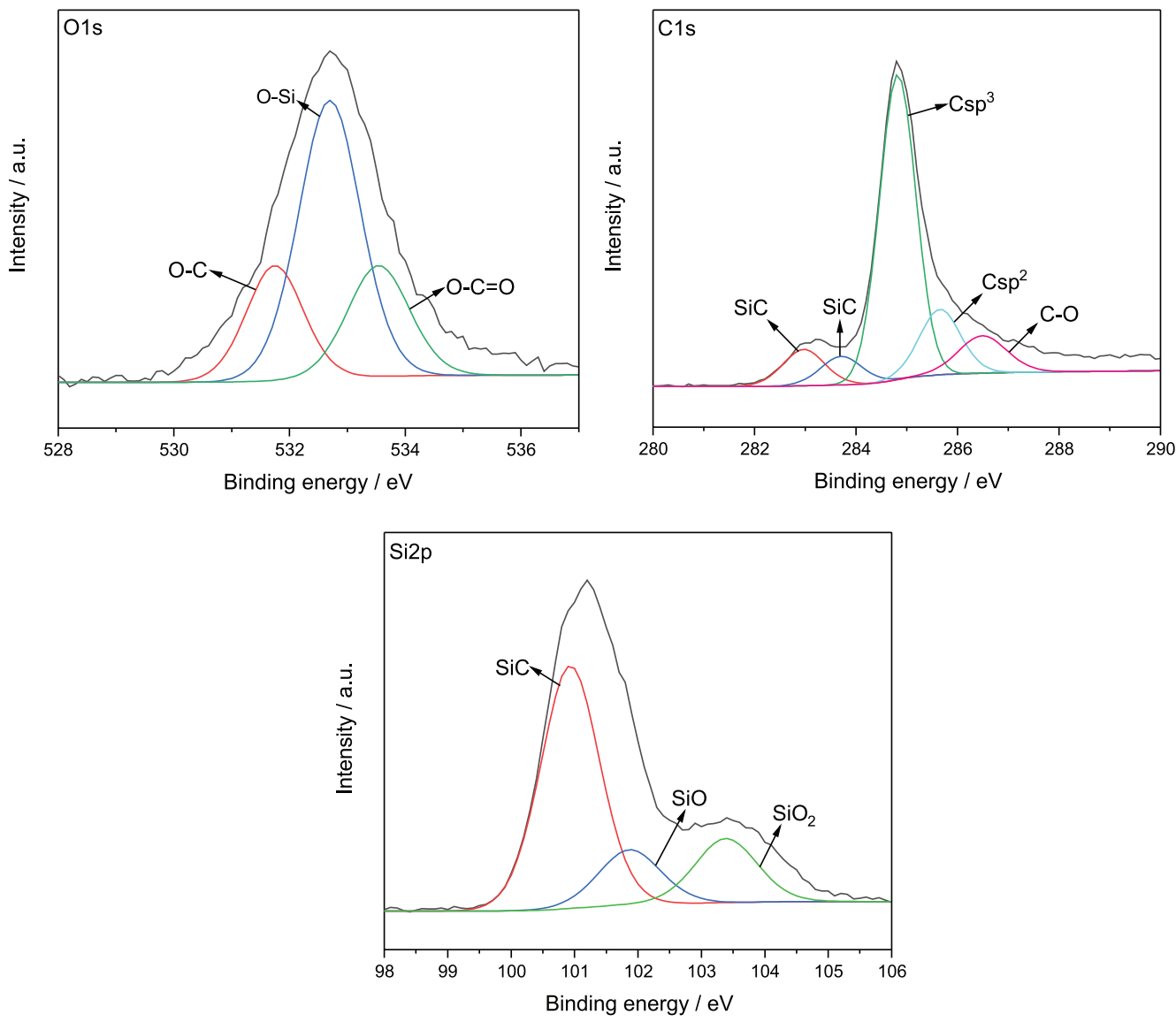

Figure 7. Deconvoluted XPS envelopes of $\mathrm{CPS}_{0 \_} 1 \mathrm{~h}$ sample for $\mathrm{O} 1 \mathrm{~s}, \mathrm{C} 1 \mathrm{~s}$ and $\mathrm{Si} 2 \mathrm{p}$ elements to illustrate different chemical species present into ceramics prepared.

diminishing of amorphous fraction composed of $\mathrm{Si}-\mathrm{O}-$-rich bonds, as verified in XRD patterns (Figure 5 and Table 5). This trend also corroborated with FTIR spectra (Figures $4 \mathrm{a}-4 \mathrm{~d}$ ), in which more intense bands assigned to $v(\mathrm{Si}-\mathrm{C})$ and $v(\mathrm{Si}-\mathrm{O}-\mathrm{Si})$ were verified for CPS and CMS, respectively.

By analyzing the total percentage of each element (Table 7), the highest and lowest carbon values were obtained for respective CPS and CMS, remaining intermediate values for CVS ceramics, corroborating with the different degradation profiles of organic groups present in the precursor structure, as observed by the TGA data. In the same way, oxygen percentages followed the trends earlier described for $\mathrm{Si}-\mathrm{O}$ bond (CMS > CVS > CPS). Despite ceramics revealed no pronounced differences among $\mathrm{C}_{\text {free }}$ amounts (Table 6), $\mathrm{Csp}^{2}$ was more effectively generated into CPS, whilst $\mathrm{Csp}^{3}$ exhibited lower occurrence. Liao et al. ${ }^{25}$ also found strong $\mathrm{sp}^{2}$ carbon character together with a $\mathrm{sp}^{3}$ character in the free carbon network of SiBCO materials with higher carbon content, by analyzing $\mathrm{C}-\mathrm{C}-\mathrm{C}$ angular distribution data. CMS ceramics showed exactly opposite results regarding CPS and intermediate $\mathrm{Csp}^{2}$ and $\mathrm{Csp}^{3}$ values for CVS were obtained. This indicates the direct influence of organic substituent on conductive carbon phase development into resulting ceramics. Structural and electronic properties focusing on the behavior of lithiation of SiCO with different carbon contents employing firstprinciples calculations were reported by Liao et al. ${ }^{60}$ The results revealed amorphization of lithiated structures during the process of $\mathrm{Li}$ insertion and preference of $\mathrm{Li}$ atoms to bond with oxygen atoms. $\mathrm{C}-\mathrm{C}$ bonds were favored in the $\mathrm{SiCO}$ structures with high carbon contents and most of the $\mathrm{Li}$ atoms were accommodated near the free carbon structure in $\mathrm{SiCO}$, indicating a larger lithium capacity as an anode of a Li-ion battery for C-enriched SiCO. Furthermore, band gap value diminished with increasing $\mathrm{C}$ content, reflecting the great influence of free carbon network on electrochemical response.

B-containing ceramics were composed of $\mathrm{BC}_{2} \mathrm{O}, \mathrm{BCO}_{2}$ and $\mathrm{BOSi}$ bonds, with higher proportions for the latter unit, confirming the effective formation of borosiloxane bonds into SiBOC materials after boron addition. CPS ceramics revealed preferential formation of $\mathrm{B}-\mathrm{O}-\mathrm{Si}$ bonds, due to their higher percentage values, followed by CMS and CVS, although the FTIR spectra have indicated a slightly different preference order for borosiloxane bonds, 

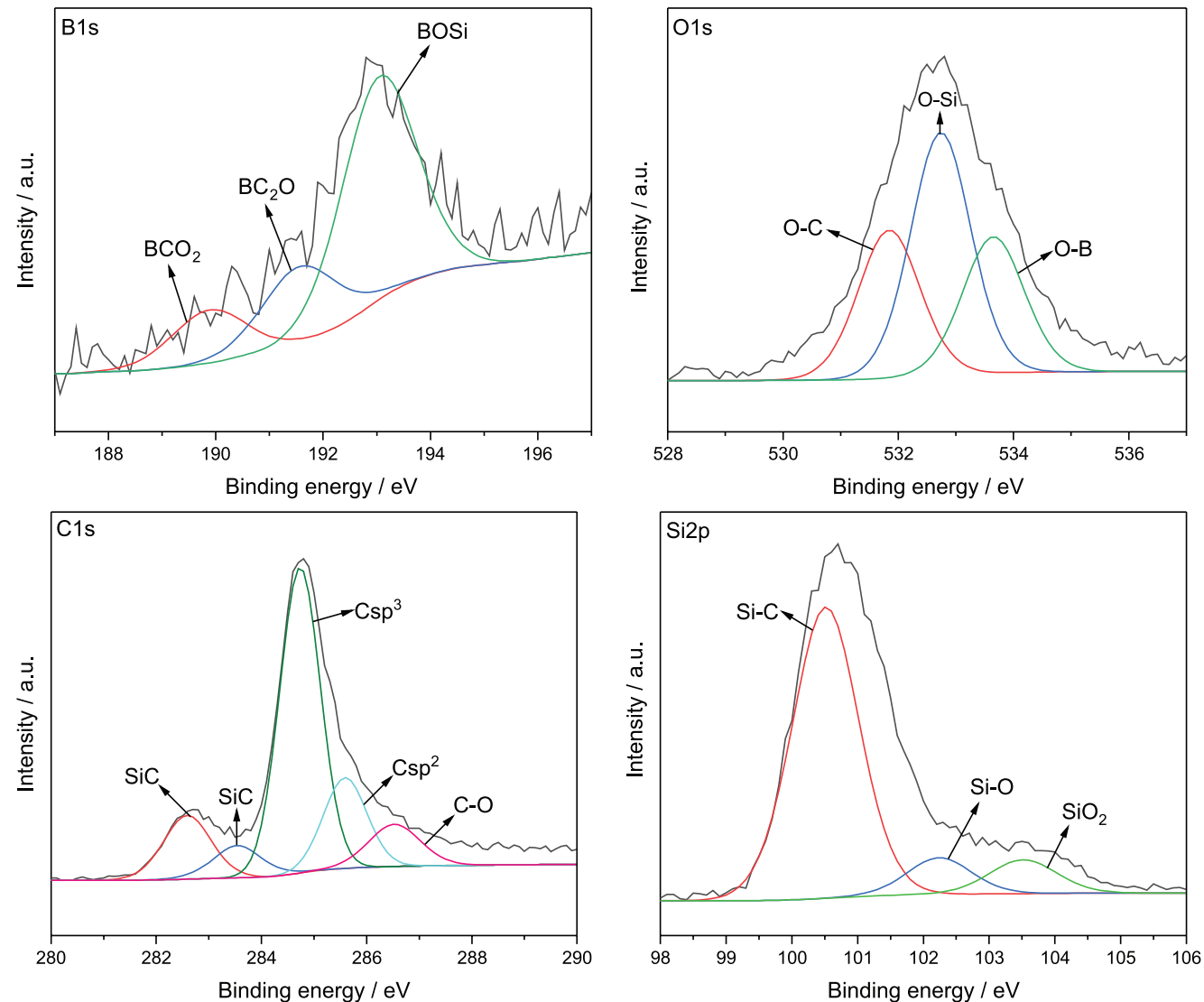

Figure 8. Deconvoluted XPS envelopes of $\mathrm{CPS}_{01 \_} 1 \mathrm{~h}$ sample for B1s, O1s, C1s and Si2p elements to illustrate different chemical species present into ceramics prepared.

Table 6. Percentages for $\mathrm{Csp}^{2}, \mathrm{Csp}^{3}$ and $\mathrm{C}_{\text {free }}$, together with $\mathrm{Si}-\mathrm{C}$ and $\mathrm{Si}-\mathrm{O}$ bonds and different trigonal boron units, obtained from deconvoluted $\mathrm{C} 1 \mathrm{~s}$, Si2p and B1s peaks integration, for CMS, CPS and CVS ceramics with and without boron pyrolyzed at $1500{ }^{\circ} \mathrm{C}$ during 1 and $3 \mathrm{~h}$ annealing

\begin{tabular}{|c|c|c|c|c|c|c|c|c|c|}
\hline \multirow{2}{*}{$\begin{array}{l}\text { Ceramic } \\
\text { material }\end{array}$} & \multicolumn{9}{|c|}{ Percentage $/ \%$} \\
\hline & $\mathrm{Csp}^{3}$ & $\mathrm{Csp}^{2}$ & $\mathrm{C}_{\text {free }}{ }^{a}$ & $\mathrm{SiC}$ & $\mathrm{SiO}$ & $\mathrm{BC}_{2} \mathrm{O}$ & $\mathrm{BCO}_{2}$ & BOSi & $\mathrm{B}_{2} \mathrm{O}_{3}$ \\
\hline $\mathrm{CMS}_{0_{-}} 1 \mathrm{~h}$ & 42.70 & 28.61 & 71.31 & 16.74 & 21.40 & - & - & - & - \\
\hline $\mathrm{CMS}_{0.1-1 \mathrm{~h}}$ & 37.00 & 29.35 & 66.35 & 14.29 & 20.35 & 20.64 & 24.60 & 54.76 & - \\
\hline $\mathrm{CMS}_{0.5-} 1 \mathrm{~h}$ & 36.81 & 27.54 & 64.35 & 5.36 & 10.00 & 9.43 & 26.97 & 63.03 & - \\
\hline $\mathrm{CMS}_{0} 3 \mathrm{~h}$ & 32.05 & 27.23 & 59.28 & 14.73 & 21.03 & - & - & - & - \\
\hline $\mathrm{CMS}_{0.1} \_3 \mathrm{~h}$ & 39.91 & 25.65 & 65.56 & 14.66 & 13.26 & 16.31 & 35.31 & 47.88 & - \\
\hline $\mathrm{CMS}_{0.5 \_} 3 \mathrm{~h}$ & 31.68 & 26.17 & 57.85 & 7.85 & 11.77 & 9.52 & 32.16 & 58.32 & - \\
\hline $\mathrm{CPS}_{0_{-}} 1 \mathrm{~h}$ & 12.66 & 51.33 & 63.99 & 65.74 & 15.83 & - & - & - & - \\
\hline $\mathrm{CPS}_{0.1-1} 1 \mathrm{~h}$ & 14.63 & 46.13 & 60.76 & 80.71 & 9.83 & 15.05 & 21.53 & 63.42 & - \\
\hline $\mathrm{CPS}_{0.5-1} 1 \mathrm{~h}$ & 11.32 & 17.24 & 28.56 & 82.72 & 11.94 & 21.15 & 17.27 & 26.43 & 35.15 \\
\hline $\mathrm{CPS}_{0} 3 \mathrm{~h}$ & 11.38 & 50.50 & 61.88 & 88.32 & 9.26 & - & - & - & - \\
\hline $\mathrm{CPS}_{0.1 \_} 3 \mathrm{~h}$ & 14.09 & 53.61 & 67.70 & 58.84 & 10.73 & 12.80 & 22.18 & 64.43 & - \\
\hline $\mathrm{CPS}_{0.5-3 \mathrm{~h}}$ & 16.27 & 27.11 & 43.38 & 92.41 & 7.59 & 16.55 & 19.72 & 63.73 & - \\
\hline $\mathrm{CVS}_{0_{-}} 1 \mathrm{~h}$ & 20.48 & 46.98 & 67.46 & 31.33 & 10.76 & - & - & - & - \\
\hline $\mathrm{CVS}_{0.1} \_1 \mathrm{~h}$ & 25.51 & 31.94 & 57.45 & 31.35 & 15.93 & 100.00 & - & - & - \\
\hline $\mathrm{CVS}_{0.5-} 1 \mathrm{~h}$ & 22.64 & 35.87 & 58.51 & 33.73 & 12.54 & 18.95 & 30.68 & 50.36 & - \\
\hline $\mathrm{CVS}_{0} 3 \mathrm{~h}$ & 19.10 & 37.59 & 56.69 & 36.96 & 19.89 & - & - & - & - \\
\hline $\mathrm{CVS}_{0.1 \_} 3 \mathrm{~h}$ & 15.29 & 39.80 & 55.09 & 41.59 & 18.16 & 100.00 & - & - & - \\
\hline $\mathrm{CVS}_{0.5-5} 3 \mathrm{~h}$ & 14.85 & 24.67 & 39.52 & 50.51 & 21.78 & 24.16 & 27.38 & 48.46 & - \\
\hline
\end{tabular}

${ }^{\mathrm{a}} \mathrm{C}_{\text {free }}=\mathrm{Csp}^{2}+\mathrm{Csp}^{3}$ 
Table 7. Total percentage of carbon, oxygen, silicon and boron, obtained from deconvoluted $\mathrm{C} 1 \mathrm{~s}, \mathrm{O} 1 \mathrm{~s}, \mathrm{Si} 2 \mathrm{p}$ and $\mathrm{B} 1 \mathrm{~s}$ peaks integration, for CMS, CPS and CVS ceramics with and without boron pyrolyzed at $1500{ }^{\circ} \mathrm{C}$ during 1 and $3 \mathrm{~h}$ annealing

\begin{tabular}{|c|c|c|c|c|}
\hline \multirow{2}{*}{$\begin{array}{l}\text { Ceramic } \\
\text { material }\end{array}$} & \multicolumn{4}{|c|}{ Total percentage / \% } \\
\hline & $\mathrm{C}$ & $\mathrm{O}$ & $\mathrm{Si}$ & B \\
\hline $\mathrm{CMS}_{0_{-}} 1 \mathrm{~h}$ & 37.31 & 37.00 & 25.69 & - \\
\hline $\mathrm{CMS}_{0.1-1 \mathrm{~h}}$ & 37.93 & 38.71 & 21.38 & 0.95 \\
\hline $\mathrm{CMS}_{0.5 \_} 1 \mathrm{~h}$ & 43.09 & 36.55 & 19.24 & 1.12 \\
\hline $\mathrm{CMS}_{0_{-}} 3 \mathrm{~h}$ & 29.96 & 42.16 & 27.88 & - \\
\hline $\mathrm{CMS}_{0.1} 3 \mathrm{~h}$ & 44.90 & 34.08 & 19.55 & 1.48 \\
\hline $\mathrm{CMS}_{0.5-3 \mathrm{~h}}$ & 45.36 & 34.99 & 18.76 & 0.85 \\
\hline $\mathrm{CPS}_{0_{-}} 1 \mathrm{~h}$ & 74.58 & 12.43 & 12.99 & - \\
\hline $\mathrm{CPS}_{0.1-1 \mathrm{~h}}$ & 68.80 & 14.06 & 15.36 & 1.78 \\
\hline $\mathrm{CPS}_{0.5-1 \mathrm{~h}}$ & 40.36 & 21.27 & 35.05 & 1.74 \\
\hline $\mathrm{CPS}_{0_{-}} 3 \mathrm{~h}$ & 76.53 & 10.06 & 13.41 & - \\
\hline $\mathrm{CPS}_{0.1 \_} 3 \mathrm{~h}$ & 73.61 & 14.47 & 10.66 & 1.25 \\
\hline $\mathrm{CPS}_{0.5-3 \mathrm{~h}}$ & 49.61 & 16.80 & 31.41 & 1.49 \\
\hline $\mathrm{CVS}_{0_{-}} 1 \mathrm{~h}$ & 44.97 & 31.58 & 23.45 & - \\
\hline $\mathrm{CVS}_{0.1-1 \mathrm{~h}}$ & 43.21 & 30.45 & 24.21 & 1.79 \\
\hline $\mathrm{CVS}_{0.5-} 1 \mathrm{~h}$ & 49.12 & 28.56 & 20.54 & 1.78 \\
\hline $\mathrm{CVS}_{0_{-}} 3 \mathrm{~h}$ & 45.64 & 27.89 & 25.26 & - \\
\hline $\mathrm{CVS}_{0.1} 3 \mathrm{~h}$ & 41.58 & 28.92 & 28.92 & 0.72 \\
\hline $\mathrm{CVS}_{0.5} 3 \mathrm{~h}$ & 37.88 & 28.98 & 31.41 & 1.20 \\
\hline
\end{tabular}

CMS > CPS > CVS (Figure 4). Interestingly, among the B-containing species, $\mathrm{B}_{2} \mathrm{O}_{3}$ phase was verified only for $\mathrm{CPS}_{0.5}$ 1h. Higher carbon amounts into matrix, as verified for CPS, favor $\mathrm{SiC}$ bonds due to greater affinity between silicon and carbon, making boron more susceptible to linkage with oxygen atoms. ${ }^{26}$ The absence of this phase in other samples might be related to the total boron amount after pyrolysis, which varied from 0.72 to $1.79 \%$ (Table 7).

Neither all ceramic samples revealed higher boron contents with increasing $\mathrm{B} / \mathrm{Si}$ ratio, indicating loss of this element during the incorporation process in the gelation step. In these cases, most of boron atoms available were still in the acid form, which suffered condensation in the drying step. ${ }^{26,48}$ However, as the B/Si ratio increased, $\mathrm{B}-\mathrm{O}-\mathrm{Si}$ proportions increased for CMS and diminished for CVS (Table 6), which were compatible with FTIR spectra for these sets of ceramics (Figures $4 \mathrm{a}-4 \mathrm{~b}$ and $4 \mathrm{e}-4 \mathrm{f}$ ). The results pointed out to the effective formation of covalent bonds in $\mathrm{Si}-\mathrm{O}-\mathrm{C}$ and $\mathrm{Si}-\mathrm{B}-\mathrm{O}-\mathrm{C}$ matrices in different extent, according to ceramic system, showing homogeneous boron incorporation via $\mathrm{B}-\mathrm{O}-\mathrm{Si}$ borosiloxane bonds.

Ceramic samples annealed for $3 \mathrm{~h}$ revealed higher $\mathrm{SiC}$ percentages regarding the analogous obtained during $1 \mathrm{~h}$, evidencing the crystallization process of silicon carbide phase as slightly stated in the XRD patterns. By comparing the two annealing conditions, higher proportions ascribed to $\mathrm{BCO}_{2}$ when compared to $\mathrm{BC}_{2} \mathrm{O}$ units were clearly verified, whilst BOSi increased for CPS and remained practically constant for CMS and CVS ceramics. These results were compatible with redistribution reactions between $\mathrm{Si}-\mathrm{O}$ and $\mathrm{B}-\mathrm{C}$ bonds, giving rise to $\mathrm{B}-\mathrm{O}-$ and $\mathrm{Si}-\mathrm{C}$-rich phases (equation 6). The evident increase in borosiloxane bonds for CPS possibly was related to more effective SiC crystallization earlier confirmed, with simultaneous formation of $\mathrm{B}-\mathrm{O}$ units.

Therefore, $\mathrm{SiC}$ and $\mathrm{C}_{\text {graphitic }}$ phases produced in different proportions into ceramic materials based on the $\mathrm{Si}-\mathrm{O}-\mathrm{C}$ and $\mathrm{Si}-\mathrm{B}-\mathrm{O}-\mathrm{C}$ systems, according to organic substituent at alkoxysilanes structure in the presence and absence of boron, demonstrated potentialities for applications as electrochemical sensors and Li-ion batteries.

\section{Conclusions}

SiOC and SiBOC ceramics were successfully prepared from pyrolysis route of MTES, PTES and VTMS precursors, with and without boric acid, at $1500{ }^{\circ} \mathrm{C}$ during 1 and $3 \mathrm{~h}$ isothermal annealing. Crystallization and composition on ceramics were evaluated in terms of organic substituent nature, boron content and annealing time.

Different crystalline profiles were noticed according to ceramic system investigated. Enhanced SiC phase crystallization for PTES-derived ceramics, followed by those containing VTMS and MTES, also confirmed by XPS measurements from percentages of bands assigned to $\mathrm{Si}-\mathrm{C}$ and $\mathrm{Si}-\mathrm{O}$ bonds, was attributed to carbon content in each polymer precursor. $\mathrm{Csp}^{2}$ and $\mathrm{Csp}^{3}$ widely varied according to precursor chemistry, revealing the highest and the lowest amounts for phenyl-groups containing ceramics, whilst those composed of methyl groups showed opposite results.

Boron was incorporated into SiBOC materials via stable borosiloxane bonds, in different extent, which were confirmed through percentages of BOSi bonds according to ceramic system. Preference order for borosiloxane bonds was given from ceramics containing the following groups: methyl > phenyl > vinyl. Lower boron amounts incorporated into some ceramics were related to boron compounds evaporation during the gelation step. Furthermore, boron addition induced the growth of $\mathrm{SiC}$ crystallites, having more influence for ceramics exhibiting higher proportion of amorphous fraction and lower residual carbon amount. In the overall, the annealing time induced the growth of SiC phase and diminished the $\mathrm{C}_{\text {free }}$ content, probably due to higher consumption of carbon domains to produce $\mathrm{Si}-\mathrm{C}$ bonds containing phase. 
In summary, the combined use of boron and alkoxysilanes containing different organic substituents played a promising synthetic strategy to fabricate multicomponent ceramics with varied proportions of semiconducting $\mathrm{SiC}$ and conductive $\mathrm{C}_{\text {graphitic }}$ phases. Therefore, the produced ceramics by this approach revealed potentialities for applications in which electrical characteristics are required.

\section{Acknowledgments}

The authors acknowledge the financial support from CAPES (Brazil), CNPq (Brazil), grant 309116/20163, together with the ESPEC (Brazil), LARX (Brazil) and LADEMA (Brazil) laboratories from UEL and Photoelectron Spectroscopy Laboratory in the X-Ray Region-XPS from IQ/UFRJ.

\section{Author Contributions}

Mariana G. Segatelli was responsible for conceptualization, formal analysis, funding acquisition, project administration, resources, supervision, writing original draft, writing review and editing; Patrícia M. Sanchez for methodology, data curation, formal analysis; Lívia R. C. Silva for data curation, formal analysis, writing original draft; Maria A. Silva for formal analysis, writing review and editing; César R. T. Tarley for formal analysis, funding acquisition, resources, writing review and editing; Paulo R. C. da Silva for data curation, formal analysis, writing-review and editing; Emerson S. Ribeiro for data curation, formal analysis, writing-review and editing.

\section{References}

1. Colombo, P.; Mera, G.; Riedel, R.; Sorarù, G. D.; J. Am. Ceram. Soc. 2010, 93, 1805.

2. Wen, Q.; Yu, Z.; Riedel, R.; Prog. Mater. Sci. 2020, 109, 100623.

3. Wang, X.; Gong, C.; Fan, G.; Mater. Res. Bull. 2011, 46, 2398.

4. Chlup, Z.; Černý, M.; Strachota, A.; Sucharda, Z.; Halasová, M.; Dlouhý, I.; J. Eur. Ceram. Soc. 2014, 34, 3389.

5. Mazo, M. A.; Padilla, I.; Tamayo, A.; Robla, J. I.; LópezDelgado, A.; Rubio, J.; Sol. Energy 2018, 173, 256.

6. Yang, H.; Li, C.; Yue, X.; Huo, J.; Ye, F.; Liu, J.; Shi, F.; Ma, J.; Mater. Des. 2020, 185, 108217.

7. Tahir, M. S.; Weinberger, M.; Balasubramanian, P.; Diemant, T.; Behm, R. J.; Lindén, M.; Wohlfahrt-Mehrens, M.; J. Mater. Chem. A 2017, 5, 10190.

8. Godoy, N. V.; Pereira, J. L.; Duarte, E. H.; Tarley, C. R. T.; Segatelli, M. G.; Mater. Chem. Phys. 2016, 175, 33.
9. Memon, F. A.; Morichetti, F.; Cantoni, M.; Somaschini, C.; Asa, M.; Bertacco, R.; Chowdhry, B. S.; Melloni, A.; J. Lightwave Technol. 2020, 38, 784.

10. Flores, L. F.; Tucto, K. Y.; Guerra, J. A.; Töfflinger, J. A.; Serquen, E. S.; Osvet, A.; Batentschuk, M.; Winnacker, A.; Grieseler, R.; Weingärtner, R.; Opt. Mater. 2019, 92, 16.

11. Li, X.; Feng, J.; Jiang, Y.; Li, L.; Feng, J.; Ceram. Int. 2019, 45, 9704.

12. Bik, M.; Gil, A.; Stygar, M.; Dąbrowa, J.; Jeleń, P.; Długoń, E.; Leśniak, M.; Sitarz, M.; Intermetallics 2019, 105, 29.

13. Zhang, Z.; Bao, Y.; Sun, X.; Chen, K.; Zhou, M.; He, L.; Huang, Q.; Huang, Z.; Chai, Z.; Song, Y.; ACS Omega 2020, 5, 11100.

14. Schelm, K.; Morales, E. A.; Scheffler, M.; Materials 2019, 12, 1870.

15. Iastrenski, M. F.; da Silva, P. R. C.; Tarley, C. R. T.; Segatelli, M. G.; Ceram. Int. 2019, 45, 21698.

16. Sasikumar, P. V. W.; Zera, E.; Graczyk-Zajac, M.; Riedel, R.; Soraru, G. D.; Dunn, B.; J. Am. Ceram. Soc. 2016, 99, 2977.

17. Duan, L.; Ma, Q.; Ceram. Int. 2012, 38, 2667.

18. Oteo, J. L.; Mazo, M. A.; Palencia, C.; Rubio, F.; Rubio, J.; J. Nano Res. 2011, 14, 27.

19. Yang, X.; Jiang, P.; Sun, F.; Yang, L.; Fan, X.; Ceram. Int. 2020, 46, 10392.

20. Schiavon, M. A.; Ferrari, J. L.; Hojamberdiev, M.; Yoshida, I. V. P.; Quim. Nova 2015, 38, 972.

21. Stabler, C.; Ionescu, E.; Graczyk-Zajac, M.; Gonzalo-Juan, I.; Riedel, R.; J. Am. Ceram. Soc. 2018, 101, 4817.

22. Saha, A.; Raj, R.; J. Am. Ceram. Soc. 2007, 90, 578.

23. Sorarù, G. D.; Pena-Alonso, R.; Leoni, M.; Microporous Mesoporous Mater. 2013, 172, 125.

24. Kleebe, H.-J.; Blum, Y. D.; J. Eur. Ceram. Soc. 2008, 28, 1037.

25. Liao, N.; Xue, W.; Zhou, H.; Zhang, M.; J. Alloys Compd. 2014, $610,45$.

26. Sreejith, K. J.; Prabhakaran, P. V.; Laly, K. P.; Dimple, R.; Packirisamy, S.; Ceram. Int. 2016, 42, 15285.

27. Klonczynski, A.; Schneider, G.; Riedel, R.; Theissmann, R.; Adv. Eng. Mater. 2004, 6, 64.

28. Sorarù, G. D.; Babonneau, F.; Gervais, C.; Dallabona, N.; J. Sol-Gel Sci. Technol. 2000, 18, 11.

29. Liebau, V.; Hauser, R.; Riedel, R.; C. R. Chim. 2004, 7, 463.

30. Zhang, X.; Liu, C.; Hong, C.; Han, J.; Han, W.; Du, S.; Ceram. Int. 2015, 41, 15292.

31. Gencer, A.; Oksal, B. S.; J. Sol-Gel Sci. Technol. 2014, 73, 171.

32. Tamayo, A.; Peña-Alonso, R.; Rubio, F.; Rubio, J.; Oteo, J. L.; J. Non-Cryst. Solids 2012, 358, 155.

33. Siqueira, R. L.; Yoshida, I. V. P.; Pardini, L. C.; Schiavon, M. A.; Mater. Res. 2007, 10, 147.

34. Schiavon, M. A.; Gervais, C.; Babonneau, F.; Soraru, G. D.; J. Am. Ceram. Soc. 2004, 87, 203. 
35. Bai, H. W.; Wen, G.; Huang, X. X.; Han, Z. X.; Zhong, B.; Hu, Z. X.; Zhang, X. D.; J. Eur. Ceram. Soc. 2011, 31, 931.

36. Wang, L.; Lu, K.; Ma, R.; Appl. Phys. A: Mater. Sci. Process. 2019, 125, DOI: 10.1007/s00339-019-2680-z.

37. Cordelair, J.; Greil, P.; J. Eur. Ceram. Soc. 2000, 20, 1947.

38. Sorarù, G. D.; Dallabona, N.; Gervais, C.; Babonneau, F.; Chem. Mater. 1999, 11, 910.

39. Gervais, C.; Babonneau, F.; Dallabonna, N.; Sorarù, G. D.; J. Am. Ceram. Soc. 2001, 84, 2160.

40. Peña-Alonso, R.; Sorarù, G. D.; J. Sol-Gel Sci. Technol. 2007, $43,313$.

41. Trezza, M. A.; Mater. Res. 2007, 10, 331.

42. Peña-Alonso, R.; Mariotto, G.; Gervais, C.; Babonneau, F.; Soraru, G. D.; Chem. Mater. 2007, 19, 5694.

43. Wen, Q.; Xu, Y.; Xu, B.; Fasel, C.; Guillon, O.; Buntkowsky, G.; Yu, Z.; Riedel, R.; Ionescu, E.; Nanoscale 2014, 6, 13678.

44. Xu, T.; Ma, Q.; Chen, Z.; Ceram. Int. 2011, 37, 2555.

45. Ionescu, E.; Kleebe, H. J.; Riedel, R.; Chem. Soc. Rev. 2012, $41,5032$.

46. Cullity, B. D.; Stock, S. R.; Elements of X-Ray Diffraction, $3^{\text {rd }}$ ed.; Pearson Education Limited: London, UK, 2014.

47. Larson, G. L.; Arkles, B.; Silicon Compounds: Silanes and Silicones, $3^{\text {rd }}$ ed.; Gelest Inc.: Morrisville, 2013, p. 175.

48. Shawgi, N.; Li, S. X.; Wang, S.; Wang, Z.; Nie, Y. N.; J. Sol-Gel Sci. Technol. 2017, 82, 450.

49. Ambadas, G.; Packirisamy, S.; Ninan, K. N.; J. Mater. Sci. Lett. 2002, 21, 1003.
50. Hasik, M.; Wójcik-Bania, M.; Nyczyk, A.; Gumuła, T.; React. Funct. Polym. 2013, 73, 779.

51. Mazo, M. A.; Tamayo, A.; Rubio, F.; Soriano, D.; Rubio, J.; J. Non-Cryst. Solids 2014, 391, 23.

52. Mazo, M. A.; Tamayo, A.; Rubio, J.; J. Eur. Ceram. Soc. 2016, $36,2443$.

53. Liao, N.; Xue, W.; Zhang, M.; J. Eur. Ceram. Soc. 2012, 32, 1275.

54. Wang, Y.; Li, H.; Zhang, L.; Cheng, L.; Ceram. Int. 2009, 35, 1129.

55. Fukui, H.; Ohsuka, H.; Hino, T.; Kanamura, K.; ACS Appl. Mater. Interfaces 2010, 2, 999.

56. Brequel, H.; Parmentier, J.; Sorarù, G. D.; Schiffini, L.; Enzo, S.; Nanostruct. Mater. 1999, 11, 721.

57. Sorarù, G. D.; Pena-Alonso, R.; Kleebe, H. J.; J. Eur. Ceram. Soc. 2012, 32, 1751.

58. Lewandowska-Łańcucka, J.; Staszewska, M.; Szuwarzyński, M.; Zapotoczny, S.; Kepczynski, M.; Olejniczak, Z.; Sulikowski, B.; Nowakowska, M.; Mater. Des. 2018, 146, 57.

59. Lyu, Y.; Tang, H.; Zhao, G.; J. Eur. Ceram. Soc. 2020, 40, 324.

60. Liao, N.; Zheng, B.; Zhou, H.; Xue, W.; J. Mater. Chem. A 2015, 3,5067 .

Submitted: October 13, 2020

Published online: February 17, 2021 